\title{
Factors predicting persistence of early wheezing through childhood and adolescence: a systematic review of the literature
}

This article was published in the following Dove Press journal:

Journal of Asthma and Allergy

27 March 2017

Number of times this article has been viewed

\author{
Carlos E \\ Rodríguez-Martínez ${ }^{1,2}$ \\ Monica P Sossa-Briceño 3 \\ Jose A Castro-Rodriguez ${ }^{4}$ \\ 'Department of Pediatrics, \\ School of Medicine, Universidad \\ Nacional de Colombia, Bogota, \\ Colombia; ${ }^{2}$ Department of Pediatric \\ Pulmonology and Pediatric Critical \\ Care Medicine, School of Medicine, \\ Universidad El Bosque, Bogota, \\ Colombia; ${ }^{3}$ Department of Internal \\ Medicine, School of Medicine, \\ Universidad Nacional de Colombia, \\ Bogota, Colombia; ${ }^{4}$ Division of \\ Pediatrics, School of Medicine, \\ Pontificia Universidad Católica de \\ Chile, Santiago, Chile
}

Background: For the early identification of persistent asthma symptoms among young children with recurrent wheezing, it would be helpful to identify all available studies that have identified at least one factor for predicting the persistence of early wheezing. The objective of the present study was to perform a systematic review of all studies that have identified factors that predict the persistence of symptoms among young patients with recurring wheezing.

Methods: A systematic review of relevant studies was conducted through searching in MEDLINE, EMBASE, CINHAL, and SCOPUS databases up to June 2016. Studies that identified predictors of persistence of wheezing illness among young children with recurrent wheezing were retrieved. Two independent reviewers screened the literature and extracted relevant data. Results: The literature search returned 649 references, 619 of which were excluded due to their irrelevance. Five additional studies were identified from reference lists, and 35 studies were finally included in the review. Among all the identified predictors, the most frequently identified ones were the following: family asthma or atopy; personal history of atopic diseases; allergic sensitization early in life; and frequency, clinical pattern, or severity of wheezing/symptoms.

Conclusion: Parental asthma (especially maternal), parental allergy, eczema, allergic rhinitis, persistent wheezing, wheeze without colds, exercise-induced wheeze, severe wheezing episodes, allergic sensitization (especially polysensitization), eosinophils (blood or eosinophil cationic protein in nasal sample), and fraction of exhaled nitric oxide were risk factors predicting persistence of early wheezing through school age. All of them are included in conventional algorithms, for example, Asthma Predictive Index and its modifications, for predicting future asthma.

Keywords: birth cohort, infantile asthma, longitudinal studies, persistence, continuance, prognosis

\section{Introduction}

Recurrent wheezing disorders in infants and preschoolers are among the most common clinical problems, generally producing a considerable impact not only on the affected children and their parents but also on the society as a whole. ${ }^{1}$ Although many of those young children who suffer from several episodes of wheezing during their first months or years of life outgrow their wheezing, a significant proportion of them will suffer from persistence of wheezing throughout childhood and/or adolescence. ${ }^{2}$ Persistent wheezing or asthma symptoms could be associated with undesirable long-term consequences, such as alterations in respiratory function and deficits in airway function and growth. Early identification of children with persistent wheezing could allow for better targeting of secondary preventive measures or appropriate therapeutic interventions, such as a prolonged or aggressive therapy for those who are most likely to benefit.
Correspondence: Carlos E

Rodríguez-Martínez

Avenida Calle 127 No. 20-78, Bogota,

Colombia

Tel +57 I 259550 I

Fax +57 I 2595520

Email carerodriguezmar@unal.edu.co 
Some algorithms have been proposed to aid in the early identification of infants and preschoolers with recurrent wheezing who are at high risk of persistent wheezing. Among these, the Asthma Predictive Index (API) is by far the most used. The API is a composite score that includes the following variables: physician-diagnosed parental asthma, physiciandiagnosed childhood eczema, physician-diagnosed allergic rhinitis, wheezing apart from colds, and blood eosinophilia. ${ }^{3}$ Although the API has been widely considered useful for early asthma diagnosis among young children with recurrent wheezing, recommendations have been made for improving its predictive ability. Two of these recommendations are a more precise definition of risk factors and an addition of exposures and interactions of exposures to other risk factors. ${ }^{4}$ Additionally, it has been suggested that given the great heterogeneity of mechanisms and risk factors for wheezing disorders, multiple algorithms are likely necessary to predict persistence of wheezing in children with early wheezing with sufficient confidence. ${ }^{5}$ One potentially useful method for achieving all the goals mentioned is to first identify all of the possible predictors of persistent wheezing illness.

For this purpose, it would be helpful to perform a systematic review of all available studies that have identified at least one factor for predicting persistence of early wheezing throughout childhood and adolescence. Presently, no single study exists that systematically identifies all of the described predictors of symptom persistence among young patients with recurring wheezing.

Therefore, the aim of this research project was to identify all the factors predicting persistence of early wheezing throughout childhood and adolescence by performing a systematic review of the literature.

\section{Methods}

\section{Search methods for identification of studies}

Published studies were identified from four databases, MEDLINE, EMBASE, CINHAL, and SCOPUS, up to June 2016 using the terms ((“Disease Progression"[Mesh]) OR predictors of persistence) AND ("Asthma"[Mesh] OR recurrent wheezing), and the search was further refined using two filters for studies: humans and children (from birth to 18 years). We included citations in any language. Furthermore, article references were searched for additional relevant publications. We considered those observational cohort studies following young children (up to 5 years of age) with recurrent wheezing throughout childhood or adolescence for assessing the persistence of wheezing illness to be eligible for inclusion.
We excluded those studies performed on children with their first episode of wheezing, or asymptomatic children but considered genetically at risk for asthma development, or children with a sole cough without recurrent wheezing. At the same time, we excluded studies published solely in abstract, due to the difficulty of analyzing their methods and results.

\section{Data extraction and assessment of quality of studies:}

Two authors (CER-M and JAC-R) independently screened the titles and abstracts of all studies obtained from the search for eligibility, according to the inclusion criteria mentioned. The full-text copy of studies deemed potentially eligible for the initial screening was evaluated to determine final eligibility. Disagreements were discussed and resolved by consensus, and when necessary, advice was sought from the third review author. Variables predicting persistence of wheezing illness were extracted from the eligible studies. Two independent reviewers (CER-M and JAC-R) critically appraised the included studies using the Strengthening the Reporting of Observational Studies in Epidemiology (STROBE) instrument. This instrument consists of 22 items that assess study description, risk of bias and confounding, statistical analyses, and generalizability. ${ }^{6}$

\section{Results}

\section{Results of the search and quality of the included studies}

Figure 1 shows the study selection process. The systematic search of databases retrieved 649 studies. Among those, we excluded 619 studies. We identified 12 additional potentially relevant studies from reference lists, of which five finally met the inclusion criteria. In the end, 35 studies reporting factors predicting persistence of early wheezing throughout childhood and adolescence were included in the review. When using the STROBE instrument, the overall quality of the included studies in the review was judged as "high risk of bias" (no or insufficient reporting on the item), "unclear risk of bias" (unclear manner of reporting), or "low risk of bias" (appropriate manner of reporting on the item). This was evaluated for all 22 items of the STROBE instrument and for each included study (Figure 2). Eight individual items were judged as low risk of bias for all studies. The individual item with the higher risk of bias was the reporting on how the study size was arrived at. Two individual items were judged as not applicable for almost all included studies. The complete list of STROBE item ratings per included study is available in the Supplementary material. 


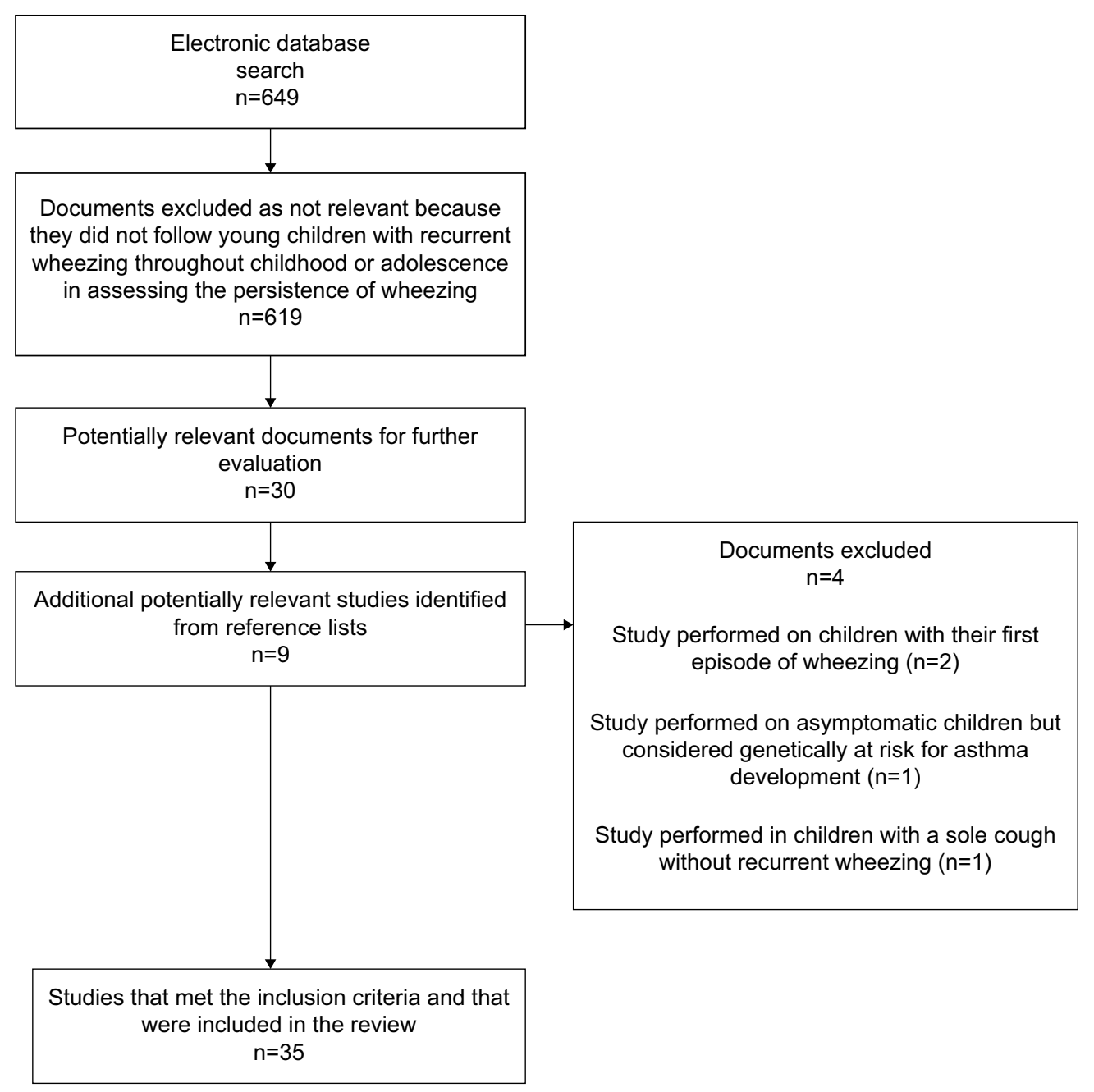

Figure I Study flow diagram showing selection of studies reporting factors predicting persistence of early wheezing throughout childhood and adolescence.

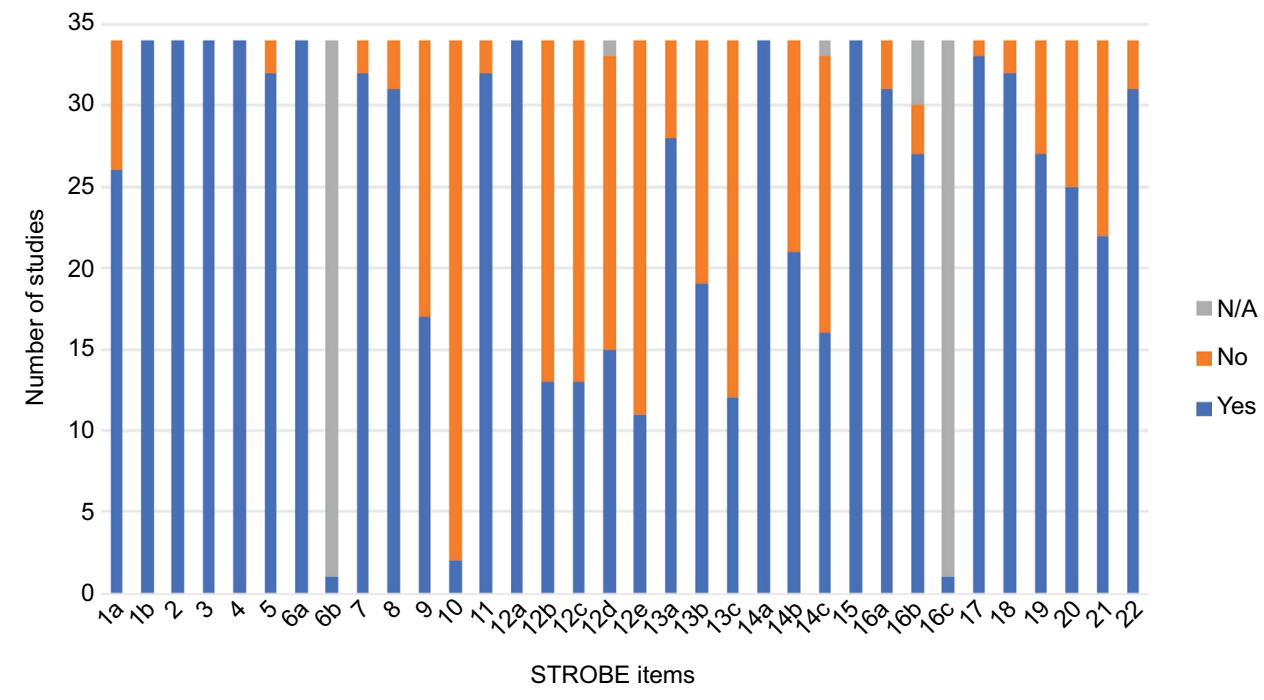

Figure 2 Assessment of quality of included studies.

Notes: STROBE: No: not reported; N/A: not applicable to the study; Yes: reported in the article.

Abbreviation: STROBE, Strengthening the Reporting of Observational Studies in Epidemiology. 


\section{Identified predictors of persistent wheezing}

\section{Family asthma or atopy}

Martinez et al, in the Tucson Children's Respiratory Study (TCRS), a large unselected longitudinal study of 1246 healthy infants enrolled at birth, reported that maternal asthma was associated (odds ratio $[\mathrm{OR}]=4.1 ; 95 \%$ confidence interval [CI] [2.1-7.9]) with persistent wheezing at the age of 6 years. ${ }^{7}$ Castro-Rodriguez et al, based on the TCRS, constructed the API, an algorithm for predicting asthma during the school years among preschoolers with recurrent wheezing episodes during the first 3 years of life. Parental history of physiciandiagnosed asthma was one of the two major criteria in the API. ${ }^{3}$ Modifications of the first API that resulted in the modified Asthma Predictive Index (mAPI), ${ }^{8}$ the University of Cincinnati Asthma Predictive Index (ucAPI), ${ }^{9}$ and the Asthma Detection and Monitoring (ADEM) API ${ }^{9}$ also included parental history of physician-diagnosed asthma as a major criterion. Hafkamp-de Groen et al performed an external validation of a modified version of the Prevention and Incidence of Asthma and Mite Allergy (PIAMA) risk score in a population of 2877 preschoolers. Parental asthma was the third strongest multivariable predictor of asthma at 6 years $(\mathrm{OR}=2.6 ; 95 \% \mathrm{CI}$ : 1.8-3.7). ${ }^{10}$ Kurukulaaratchy et al identified asthmatic family history as an independent predictor of wheezing persistence from the first 4 years to the age of 10 years (OR=2.31; $95 \%$ CI: $1.22-4.37 ; p=0.01)$, in a study of 1456 participants in a whole-population birth cohort, carried out on the Isle of Wight in $1989 .{ }^{11}$ Matricardi et al, in the German birth cohort Multicentre Allergy Study (MAS) which followed 441 children with wheezing before the age of 3 years, reported that parental atopy (including asthma, hay fever, and atopic dermatitis) was an independent predictor of wheezing at the age of $11-13$ years $(\mathrm{OR}=8.32 ; 95 \% \mathrm{CI}: 2.74-25.20 ; p<0.001) .{ }^{12}$ Just et al prospectively followed a cohort of 219 wheezy infants aged $\leq 30$ months and found that a parent with asthma was an independent predictor of persistence of wheezing at the age of 6 years (OR=2.34; 95\% CI: $1.06-5.17 ; p=0.03){ }^{13}$ Henderson et al used latent class analysis (LCA) to assign phenotypes based on patterns of wheezing in 6265 children participating in the Avon Longitudinal Study of Parents and Children (ALSPAC), a longitudinal population-based birth cohort of children born in Avon, England. They reported that maternal asthma (OR=4.17; 95\% CI: 3.12-5.56) and maternal allergy (OR=2.09; 95\% CI: 1.67-2.62) were associated with the persistent wheeze phenotype.$^{14}$ Caudri et al also used LCA to identify different wheezing phenotypes in children aged $0-8$ years in the PIAMA birth cohort and found that maternal allergy ( $\mathrm{OR}=2.06 ; 95 \% \mathrm{CI}: 1.36-3.12)$ and paternal allergy $(\mathrm{OR}=1.74 ; 95 \% \mathrm{CI}: 1.15-2.63)$ were independent predictors of the persistent wheeze phenotype. ${ }^{15}$ Vial Dupuy et al, in a population of 200 infants under 2 years of age diagnosed with recurrent wheezing, reported that family history of asthma was an independent predictor of persistent asthma at the age of 6 years $(\mathrm{OR}=2.4 ; 95 \% \mathrm{CI}: 1.3-4.5 ; p=0.007)$, and this was one of the three predictor variables included in their proposed score. ${ }^{16}$ van der Mark et al, in a population of 438 children aged $1-5$ years attended in primary care for recurrent coughing, wheezing, and shortness of breath, identified that family history of asthma or allergy (asthma or allergy in parents and siblings) was one predictor variable for asthma at the age of 6 years, although it did not reach significance $(\mathrm{OR}=1.54 ; 95 \%$ CI: $0.98-2.41 ; p=0.060) .{ }^{17}$ Pescatore et al, in a study carried out in Leicestershire, UK, on a population-based cohort of 1126 children aged $1-3$ years with parent-reported wheeze or a chronic cough (a cough without colds or a cough at night) with one or more visits to the doctor for wheeze or cough during the previous 12 months, developed a tool for predicting asthma at school age. In that study, parental history of wheeze, asthma, or bronchitis was one of the ten predictors included in the tool $(\mathrm{OR}=1.23 ; p<0.001) .{ }^{18}$ Mikalsen et al, in a population of 93 children under 2 years of age hospitalized for bronchiolitis during their first year of life, reported that although recurrent wheeze was the only independent predictor of asthma at the age of 11 years $(\mathrm{OR}=7.2 ; 95 \% \mathrm{CI}$ : 1.3-41.6; $p=0.015)$, combining recurrent wheeze with either parental atopy or parental asthma improved specificity $(>80)$, positive likelihood ratio (LR) ( $>3$ ), and positive posttest probability $(50 \%)$, rendering that combination more appropriate for the prediction of later ocurrence of asthma. ${ }^{19}$ Csonka et al reported in a population of 1816 children younger than 3 years of age that family history of asthma (defined as children with a biological parent or sibling with known asthma) was independently associated $(\mathrm{OR}=1.9 ; 95 \% \mathrm{CI}: 1.3-2.8$; $p=0.001)$ with symptom persistence up to school age. ${ }^{20}$ Finally, Neuman et al aimed to identify clinical risk factors for current asthma at 8 years of age in 823 Swedish infants who wheezed during the first 2 years of life in a population-based setting. Allergic heredity was identified as one independent risk factor for school-age asthma in the population analyzed $(\mathrm{OR}=1.53 \text {; 95\% CI: } 1.02-2.30)^{21}$ (Figure 3).

\section{Personal history of atopic diseases}

Martinez et al identified eczema (OR=2.4; 95\% CI: 1.3-4.6) and rhinitis apart from colds (OR=2.0; 95\% CI: $1.2-3.2)$ as independent predictors of persistent wheezing at the age 


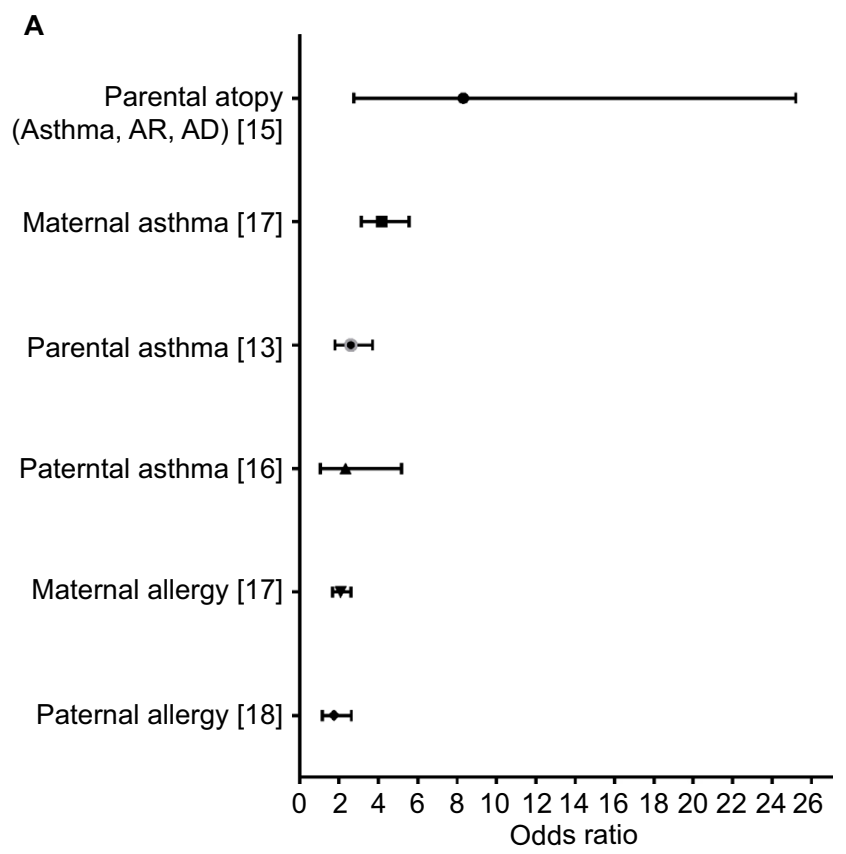

B

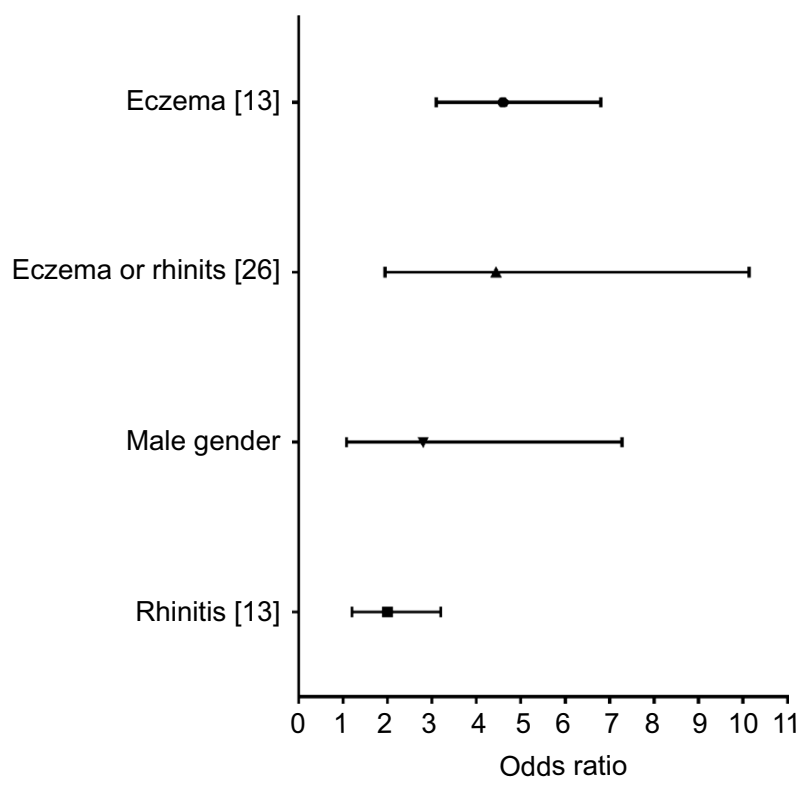

Figure 3 OR and $95 \%$ confidence interval for predictors of persistence of symptoms among young patients with recurring wheezing: (A) parental asthma and allergic diseases; and (B) gender, eczema, and rhinitis.

Note: For this figure, we chose only the highest OR for each parameter among the studies.

Abbreviations: $O R$, odds ratio; $A R$, allergic rhinits; $A D$, atopic dermatitis.

of 6 years. $^{7}$ A medical diagnosis of eczema and a medical diagnosis of allergic rhinitis were two of the five included parameters in the API, the former as a major criterion and the latter as a minor criterion. ${ }^{3}$ The mAPI also included a medical diagnosis of eczema as a major criterion, although it changed allergic rhinitis to sensitization to milk, egg, or peanut as a minor criterion. ${ }^{22}$ The ucAPI also included a medical diagnosis of eczema and physician-diagnosed allergic rhinitis as a major and a minor criterion, respectively. ${ }^{9}$ Medical diagnosis of eczema as a major and allergic rhinitis as a minor criterion were used in the ADEM API. ${ }^{23}$ Caudri et al followed 3963 children for 8 years in the PIAMA birth cohort in order to develop a score for predicting the risk of asthma at 7-8 years of age. Eczema (doctor's diagnosis of eczema and eczematous rash present) was an independent predictor of asthma $(\mathrm{OR}=2.3 ; 95 \% \mathrm{CI}: 1.7-3.1)$ and was one of the eight clinical parameters that composed the risk score, accounting for 8.2 of a total of 55.1 points in the prediction score. ${ }^{24}$ The modified version of the PIAMA risk score identified eczema as the second strongest multivariable predictor of asthma at 6 years of age $(\mathrm{OR}=4.6 ; 95 \% \mathrm{CI}: 3.1-6.8) .{ }^{10}$ Frank et al followed a population of 628 children aged $<5$ years over a period of 6-11 years and indicated that a history of atopic disorders (hay fever or eczema) was one of the two significant baseline predictors of persistent asthma $(\mathrm{OR}=4.44 ; 95 \% \mathrm{CI}$ : $1.94-10.13 ; p<0.001) .{ }^{25}$ Amat et al, in a study of 227 children under 36 months of age with a history of at least three wheezing episodes, established that initial atopic dermatitis was an independent predictor $(\mathrm{OR}=3.4$; 95\% CI: $1.9-6.3$; $p<0.001)$ for active asthma at 13 years of age $(\mathrm{OR}=3.4 ; 95 \%$ CI: $1.9-6.3 ; p<0.001) .{ }^{26}$ Vial Dupuy et al reported that atopic dermatitis was an independent predictor $(\mathrm{OR}=2.3 ; 95 \% \mathrm{CI}$ : $1.2-4.5 ; p=0.01$ ) of persistent asthma at 6 years of age, and this was one of the three predictor variables included in the predictive score. ${ }^{16}$ Pescatore et al proposed eczema as one of the ten predictors $(\mathrm{OR}=1.52 ; p<0.001)$ included in their tool for predicting asthma. ${ }^{18}$ Csonka et al identified itchy rash as an independent predictor of symptom persistence up to school age in a population of children younger than 3 years with recurrent wheezing $(\mathrm{OR}=2.2 ; 95 \% \mathrm{CI}$ : $1.6-3.2$; $p<0.001) .{ }^{20}$ Reijonen et al followed a population of 89 infants under 2 years of age hospitalized for respiratory infections associated with wheezing in order to assess the development of asthma 3 years after hospitalization. Atopic dermatitis on entry significantly predicted asthma at the median age of 4 years $(\mathrm{OR}=3.4 ; 95 \%$ CI: $1.17-9.39 ; p=0.023) .{ }^{27}$ Finally, infant eczema was identified as an independent predictor of active asthma at 8 years of age in a population-based birth cohort $(\mathrm{OR}=2.31 ; 95 \% \mathrm{CI}: 1.52-3.49)^{21}$ (Figure 3).

\section{Allergic sensitization early in life}

The mAPI used allergic sensitization to one aeroallergen as a major criterion in a 5-1 clinical trial, ${ }^{8}$ and allergic sensitization to milk, eggs, or peanuts as a minor criterion. ${ }^{22}$ 
Likewise, the ucAPI also included allergic sensitization to one aeroallergen as a major criterion and allergic sensitization to milk or eggs as a minor criterion. ${ }^{9}$ In this same study, allergic persistent wheezing (defined as having persistent wheezing with one or more skin prick tests (SPTs) positive for 15 of the local common aeroallergens) was associated with a significantly higher risk of asthma $(\mathrm{OR}=10.4$; 95\% CI: $4.1-26.0 ; p<0.01)$ compared to non-allergic persistent wheezing $(\mathrm{OR}=5.4 ; 95 \% \mathrm{CI}: 2.04-14.06 ; p<0.01) .{ }^{9}$ In the MAS cohort, perennial sensitization to indoor (mites, cat, and dog) allergens was a strong predictor of wheezing at 11-13 years in the multivariate analysis among early wheezers $(\mathrm{OR}=6.23$; 95\% CI: $2.41-16.09 ; p<0.001) .{ }^{12}$ In the ALSPAC cohort, any skin prick sensitivity $(\mathrm{OR}=3.64 ; 95 \% \mathrm{CI}: 2.76-4.81)$, skin prick sensitivity to Dermatophagoides pteronyssinus ( $\mathrm{OR}=4.66$; 95\% CI: 3.42-6.36), skin prick sensitivity to cat $(\mathrm{OR}=7.54 ; 95 \% \mathrm{CI}: 5.17-11.00)$, and skin prick sensitivity to grass $(\mathrm{OR}=3.27 ; 95 \% \mathrm{CI}: 2.37-4.53)$ were significantly associated with the persistent wheeze phenotype. ${ }^{14}$ In the Isle of Wight cohort, SPT for a series of common inhaled and food allergens, including house dust mite (D. pteronyssinus), grass pollen mix, cat and dog epithelia, Alternaria alternata, Cladosporium herbarum, milk, hen's egg, soya, cod, wheat, and peanuts, was performed on a large group of children seen at 4 years. Atopic SPT at 4 years was an independent predictor of wheezing persistence from the first 4 years to the age of 10 years $(\mathrm{OR}=5.73 ; 95 \% \mathrm{CI}: 2.95-11.12 ; p<0.001) .{ }^{11}$ Just et al identified that allergic sensitization (defined as the presence of specific $\mathrm{IgE}$ against at least one common aeroallergen such as house dust mites, dog and cat dander, grass pollen, birch pollen, or food allergens such as cow's milk, hen's egg, peanut, soy, wheat, or fish) was an independent predictor of persistence of wheezing at the age of 6 years $(\mathrm{OR}=2.23$; 95\% CI: $1.20-4.12 ; p=0.01) .{ }^{13}$ Amat et al identified allergic sensitization to multiple aeroallergens (defined as two or more specific airborne allergen-positive $\operatorname{IgE} \geq 0.35 \mathrm{kU} / \mathrm{L}$ ) as an independent predictor of asthma at the age of 13 years among recurrent wheezing children aged under 36 months $(\mathrm{OR}=4.6$; 95\% CI: $1.9-11.2 ; p=0.001) .{ }^{26}$ IgE polysensitization was an independent predictor of persistent asthma at 6 years of age $(\mathrm{OR}=6.1 ; 95 \% \mathrm{CI}: 1.7-21.6 ; p=0.003)$, and was one of the three predictor variables included in the persistent asthma predictive score proposed by Vial Dupuy et al. ${ }^{16}$ van der Mark et al identified specific IgE against cats, dogs, and/or house dust mites as one of the five independent predictors of asthma diagnosis at age $6(\mathrm{OR}=2.45 ; 95 \% \mathrm{CI}$ : 1.38-4.33; $p=0.003) .{ }^{17}$ Aeroallergen-related wheeze/cough $(\mathrm{OR}=1.22 ; p<0.001)$ was one of the ten predictors included in the tool proposed by Pescatore et al. ${ }^{18}$ Food allergy was identified as an independent predictor of symptom persistence up to school age in a population of children younger than 3 years with recurrent wheezing $(\mathrm{OR}=1.8$; 95\% CI: 1.2-2.5; $p=0.002) .{ }^{20}$ Reijonen et al identified SPT positivity to indoor allergens (especially to cat or dog epithelial dander) at the age of 16 months as an independent predictor of asthma at the median age of 4 years $(\mathrm{OR}=9.5 ; 95 \% \mathrm{CI}: 2.45-36.72$; $p=0.0011) .{ }^{27}$ Finally, Caudri et al confirmed that specific $\operatorname{IgE}$ sensitization (defined as specific $\operatorname{IgE}$ of $\geq 0.70 \mathrm{IU} / \mathrm{ml}$ for at least one of six tested airborne allergens) in 4-year-old children with asthma-suggestive symptoms, independent of clinical history, predicts asthma symptoms up to the age of 8 years in the PIAMA birth cohort study $(\mathrm{OR}=2.8 ; 95 \% \mathrm{CI}$ : $1.9-4.1)^{28}$ (Figure 4).

\section{Frequency, clinical pattern, or severity of wheezing/symptoms}

In the TCRS, compared with the children with transient early wheezing, those with persistent wheezing were more likely to have wheezed often or very often $(\mathrm{OR}=2.3 ; 95 \%$ CI: $1.4-3.8 ; p=0.001) .^{7}$ Castro-Rodriguez et al reported that children with a positive loose API were 2.6-5.5 times more likely to have current asthma between ages 6 and 13 than children with a negative loose API. However, risk of having subsequent asthma increased to 4.3-9.8 times when a stringent API was used, demonstrating the importance of clinical pattern of wheezing in predicting subsequent asthma, due to the fact that the only difference between the indices is the frequency of wheeze (early wheeze for the loose API vs. early frequent wheeze for the stringent API). ${ }^{3}$ Additionally, both in the loose and the stringent API, wheezing apart from colds was included as a minor criterion. ${ }^{3}$ In the original PIAMA risk score, both wheezing frequency $(\mathrm{OR}=1.5$; 95\% CI: $1.1-2.1$ for $1-3$ times/year, and $\mathrm{OR}=2.5$; 95\% CI: $1.7-3.6$ for $\geq 4$ times/year) and wheezing/dyspnea apart from colds $(\mathrm{OR}=2.0 ; 95 \% \mathrm{CI}$ : 1.1-3.7) were included as two of the eight clinical parameters considered important for predicting asthma at 6-8 years of age. ${ }^{24}$ Likewise, in the modified version of the PIAMA risk score, wheezing frequency was also included as one of the eight clinical parameters considered important for predicting persistent asthma. ${ }^{10}$ Chang et al tested a potential mAPI modification with a two- instead of a four-wheezing episode requirement $\left(\mathrm{m}^{2} \mathrm{API}\right)$ in the same population, but this modification lowered the positive LR without meaningfully improving the negative LR. ${ }^{22}$ In the Frank et al study, baseline parentreported exercise-induced wheeze was one of the only two significant predictors of persistent asthma $(\mathrm{OR}=3.94$; 95\% CI: $1.72-9.00 ; p=0.001) .{ }^{25}$ Leonardi et al assessed the 

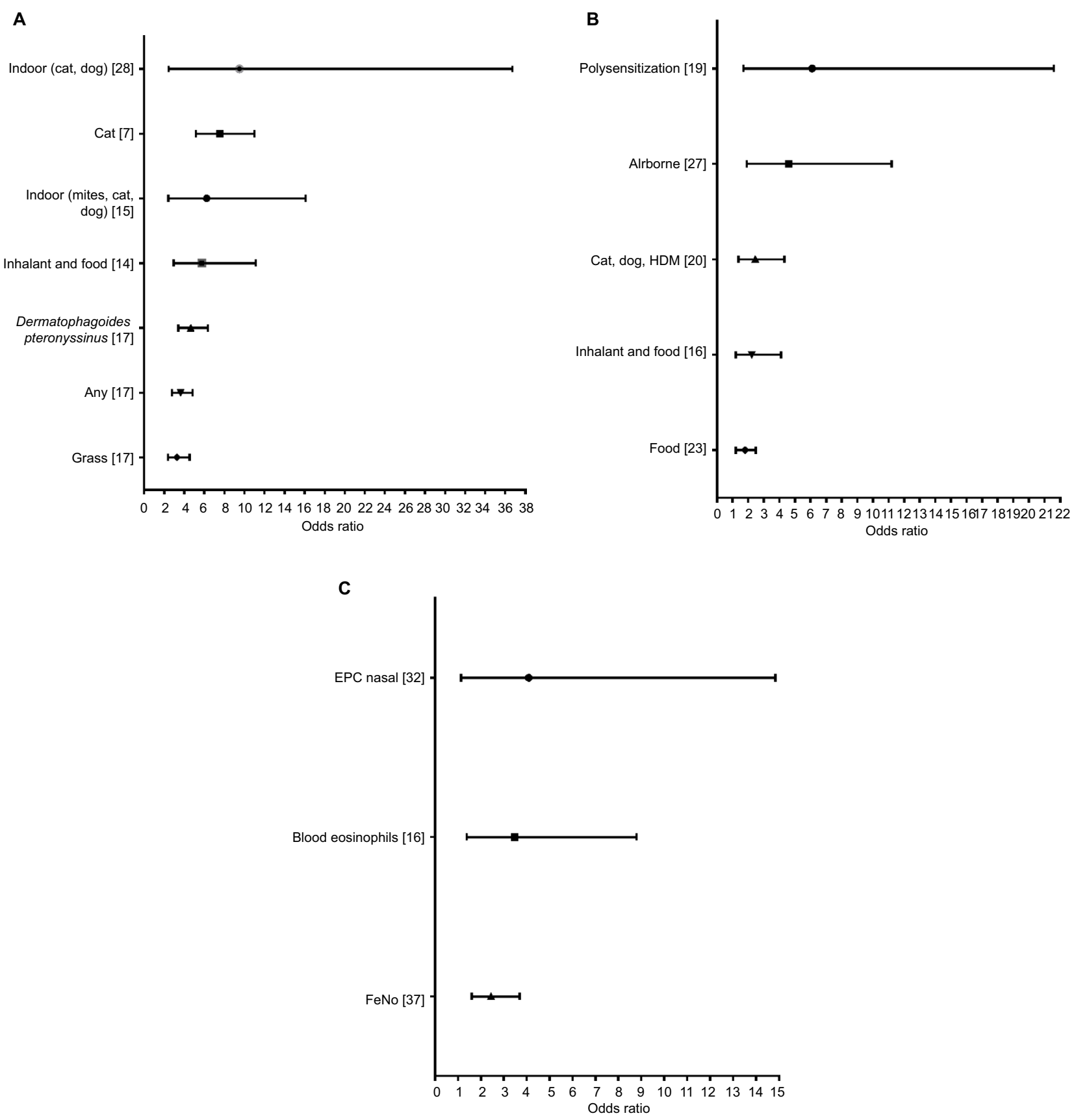

Figure 4 OR and $95 \%$ confidence interval for predictors of persistence of symptoms among young patients with recurring wheezing: (A) allergic sensitization measured by skin prick test; (B) allergic sensitization measured by specific lgE; and (C) other allergic measurements.

Note: For this figure, we chose only the highest OR for each parameter among the studies.

Abbreviations: OR, odds ratio; HDM, house dust mite; EPC, endothelial progenitor cell; FeNO, fraction of exhaled nitric oxide.

performance of simple clinical prediction rules (based on the frequency of early wheeze) for predicting current asthma at school age. They reported that persistent early frequent wheeze, the strictest prediction rule, had the highest OR ( 9.5 at the age of 7 years; 12.0 at the age of 10 years), specificity (99\% at both the ages), and positive predictive value (51\%, $55 \%$ ), but the lowest sensitivity ( $12 \%$ at both the ages) and poor discriminative ability (c statistic $<0.6) .{ }^{29}$ Amin et al confirmed that asthma at age 7 was significantly associated with the persistent wheezing phenotype (defined as two or more episodes of wheezing in the previous 12 months at both the 2- and 3-year clinic visits, or if the parent reported a history of physician-diagnosed asthma in the past 12 months at the 3-year clinic visit) at age 3 (OR=9.8; 95\% CI: 4.9-19.5; $p<0.01) .{ }^{9}$ Devulapalli et al, using a simple scoring system (based on the frequency and the persistence of episodes of bronchial obstruction and on hospitalizations for bronchial obstruction), determined that severe obstructive airway disease by the age of 2 years was a substantial risk factor for predicting asthma at 10 years of age (OR=8.0; 95\% 
CI: 4.8-13.2). ${ }^{30}$ Severe recurrent wheezing (indicated by at least two previous hospital admissions due to exacerbation) was an independent predictor of current asthma at the age of 13 years among a population of recurrent wheezing children aged under 36 months $(\mathrm{OR}=2.3 ; 95 \% \mathrm{CI}$ : $1.3-4.2$; $p=0.007) .{ }^{26}$ Wheezing-induced sleep disturbances and wheezing in the absence of a cold were identified as two of the five independent predictors of asthma diagnosis at age $6(\mathrm{OR}=2.08 ; 95 \% \mathrm{CI}: 1.31-3.29 ; p=0.002$, and $\mathrm{OR}=2.22$; 95\% CI: $1.23-3.99 ; p=0.008$, respectively). ${ }^{17}$ Wheezing without colds, exercise-related wheeze/cough (wheeze or a cough with running, playing, laughing, or crying), and more than three episodes of wheezing attacks $(\mathrm{OR}=1.40$; $p<0.001, \mathrm{OR}=1.26 ; p<0.001$, and $\mathrm{OR}=1.65 ; p<0.001$, respectively) were three of ten predictor variables included in the tool proposed for predicting asthma at school age. ${ }^{18}$ Likewise, activity disturbance and shortness of breath were two additional predictor variables included in this tool, with a major probability of asthma at school age in patients with greater severity of these two variables at baseline. ${ }^{18}$ To et al, in a longitudinal population-based cohort study, followed 28418 children diagnosed with asthma before 5 years of age (defined as one asthma hospitalization or two physician consultations within 3 years before 6 years of age) up to the age of 11 years. After adjusting for significant covariates, children with at least one asthma hospitalization during the first year post-diagnosis had a significantly higher risk of having persistent asthma compared with those without any health care encounter for asthma in the same period (OR=3.0; 95\% CI: 2.69-3.39; $p<0.001)$. Similarly, those with at least four physician visits also had a significantly higher risk of persistent asthma during follow-up (OR=2.60; 95\% CI: 2.34-2.81; $p<0.001) .{ }^{31}$ Csonka et al established that hospital treatment for wheezing when $<3$ years of age was independently associated with symptom persistence up to school age $(\mathrm{OR}=4.5 ; 95 \% \mathrm{CI}: 3.1-6.5 ; p<0.001) .{ }^{20}$ Finally, increased frequency of wheeze was identified as an independent predictor of active asthma at 8 years of age in a population-based birth cohort (OR=3.41; 95\% CI: 2.09-5.56 for children with three or more episodes compared with two or less episodes during the first 2 years of life) ${ }^{21}$ (Figure 5).

\section{Eosinophil activity}

Peripheral blood eosinophilia, defined as an eosinophil count $>4 \%$ of the total white blood cells, was considered one of the three minor criteria in both the loose and the stringent API. ${ }^{3}$ Likewise, in the mAPI, peripheral blood eosinophilia was included as a minor criterion for predicting asthma. ${ }^{22}$ Hyvarinen et al aimed to determine whether elevated blood

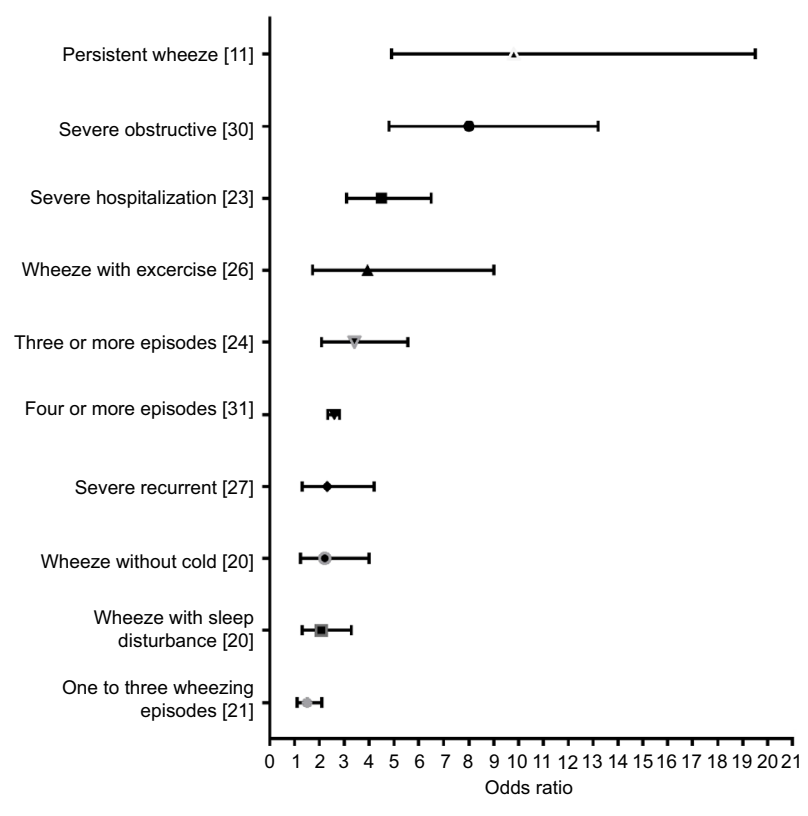

Figure 5 OR and $95 \%$ confidence interval for predictors of persistence of symptoms among young patients with recurring wheezing (patterns of wheezing).

Note: For this figure, we chose only the highest OR for each parameter among the studies.

Abbreviation: OR, odds ratio.

eosinophil count or eosinophil cationic protein in serum or in nasopharyngeal aspirate predicts future occurrence of asthma after hospitalization for wheezing in infancy in 81 infants aged $<24$ months, followed up to a median age of 12.3 years. After adjusted analyses, only elevated eosinophil cationic protein in nasopharyngeal aspirate was an independent risk factor for persistent childhood asthma $(\mathrm{OR}=4.09 ; 95 \%$ CI: $1.13-14.85 ; p=0.032) .{ }^{32}$ Blood eosinophilia $\geq 470 / \mathrm{mm}^{3}$ was an independent predictor of persistence of wheezing at the age of 6 years in a prospective cohort study $(\mathrm{OR}=3.48$; 95\% CI: $1.38-8.79 ; p=0.008) .{ }^{13}$ Hypereosinophilia (defined as an absolute eosinophil count of $\geq 470 / \mathrm{mm}^{3}$ ) was an independent predictor of active asthma at age $13(\mathrm{OR}=2.2 ; 95 \%$ CI: $1.07-4.7 ; p=0.033)^{26}$ (Figure 4).

\section{Total serum lgE level}

In the TCRS, children who started wheezing early in life and continued to wheeze at the age of 6 years had significantly higher levels of total serum IgE levels at 9 months of age compared to children who had never wheezed (5.2 IU/mm; $95 \%$ CI: $3.8-7.2$ vs. $3.4 \mathrm{IU} / \mathrm{mm}$; 95\% CI: $3.0-3.9, p<0.01))^{7,33}$

\section{Respiratory infections}

Parental reports of serious respiratory illness such as flu, infection of the throat or middle ear, sinusitis, bronchitis, or pneumonia $(\mathrm{OR}=1.6 ; 95 \% \mathrm{CI}: 1.2-2.1$ for $1-2$ times/year, and $\mathrm{OR}=2.0$; 95\% CI: $1.3-3.0$ for $\geq 3$ times/year) were included as one of the eight clinical parameters considered important 
for predicting asthma at 6-8 years of age in the PIAMA score. ${ }^{24}$ In the modified version of the PIAMA risk score, the number of respiratory tract infections (defined based on parental reports on the number of doctor's office visits caused by the child's fever in combination with a cough, a runny or blocked nose, or an earache) was also included as one of the eight clinical parameters considered important for predicting persistent asthma at the age of 6 years. ${ }^{10}$ In the Isle of Wight cohort, researchers identified that recurrent chest infections at 2 years of age (defined as more than one chest infection in the previous year, and determined on clinical grounds by one of the investigators) was an independent predictor of wheezing persistence $(\mathrm{OR}=1.99 ; 95 \% \mathrm{CI}: 1.05-3.77 ; p=0.034)$ from the first 4 years up to age $10 .^{11}$

\section{Lung function}

In the TCRS, children who started wheezing early in life and continued to wheeze at the age of 6 years had normal lung function in the first year of life, with length-adjusted maximal expiratory flow at functional residual capacity (VmaxFRC) values that were not significantly different from those of the children who never wheezed. ${ }^{7}$ In contrast, in the Antwerp Prospective Cohort on the Influence of Perinatal Factors on the Occurrence of Asthma and Allergies (PIPO) birth cohort study, the authors reported significant differences both in the baseline respiratory function and in the bronchodilator response (using forced oscillation techniques) between 325 preschool children with different wheezing phenotypes, showing that the baseline lung function was poorer and the bronchodilator response was greater in 4-year-old children with persistent wheeze than in those who had never wheezed or who had suffered from early transient wheeze. ${ }^{34}$ Furthermore, Turner et al showed that reduced neonatal lung function (measured with VmaxFRC) was associated with wheezing at the age of 4-6 years that persisted up to 11 years of age, and this relationship was independent of atopy, increased airway responsiveness in infancy and childhood, and factors that may influence VmaxFRC..$^{35}$ Delacourt et al found that persistent wheezers had significantly lower VmaxFRC values at the initial visit than infant wheezers who became asymptomatic later $(p<0.01)$, and they also had higher specific airway resistance values at the end of follow-up than did asymptomatic children. However, the level of bronchial hyperresponsiveness in infants who wheezed was not predictive of the persistence of asthma 4 years later. ${ }^{36}$ Caudri et al determined that interrupter resistance measurement in 4-year-old children with asthma-suggestive symptoms was significantly associated with wheezing at age 6 , but not at 7 and 8 years of age in children participating in the PIAMA birth cohort study. ${ }^{28}$ Finally, in the ADEM study, adding pre- and post-bronchodilator airway resistance measured by MicroRint did not make a significant contribution to the improvement of the API for predicting asthma at school age. ${ }^{9}$

\section{Gender}

In the TCRS, male gender was an independent predictor of persistent wheezing at the age of 6 years $(\mathrm{OR}=1.9$; 95\% CI: 1.2-3.0). ${ }^{7}$ Also, in the MAS, male gender was an independent predictor of wheezing at the age of $11-13$ years $(\mathrm{OR}=2.80$; 95\% CI: $1.08-7.28 ; p=0.034) .{ }^{12}$ Likewise, both in the original PIAMA risk score and its validated modified version, male gender was included as one of the eight clinical parameters considered important for predicting asthma at 6-8 years of age. ${ }^{10,24}$ Male gender was one of the two strongest predictors of the persistent wheeze phenotype in the PIAMA birth cohort (OR=2.06; 95\% CI: 1.34-3.16). ${ }^{15}$ Finally, male gender $(\mathrm{OR}=1.48 ; p<0.001)$ was one of the ten predictor variables included in the tool proposed by Pescatore et $\mathrm{al}^{18}$ (Figure 3 ).

\section{Breastfeeding}

In the PIAMA birth cohort, breastfeeding for at least 3 months was an independent protector factor for asthma persistence $(\mathrm{OR}=0.61 ; 95 \% \mathrm{CI}: 0.40-0.93) .{ }^{15}$ Likewise, Just et al identified breastfeeding for longer than 3 months as an independent protector factor for asthma persistence at the age of 6 years $(\mathrm{OR}=0.43 ; 95 \% \mathrm{CI}: 0.23-0.82 ; p=0.01) .{ }^{13}$

\section{Exhaled biomarkers of airway inflammation}

Singer et al modified the original API by replacing the minor criterion eosinophilia with the fraction of exhaled nitric oxide (FeNO) as the third major criterion. This mAPI was evaluated in a cohort of 391 children aged between 3 months and 4 years with recurrent coughing or wheezing for the efficacy of predicting asthma at school age. The authors reported that per $5 \mathrm{ppb}$ increase in FeNO at baseline, the OR (95\%CI) for asthma increased by 2.44 (1.61-3.70), without change when adjusting for confounders. ${ }^{37}$ Klaassen et al evaluated the added predictive value of exhaled biomarkers (exhaled volatile organic compounds [VOCs]) to clinical information assessed with the API, in the ADEM cohort study of 202 preschoolers with recurrent wheeze (aged 2-4 years) who were followed up to 6 years of age. The authors determined that by adding data of nine VOCs to the API, $101(83 \%)$ of the 122 children included in the discovery set were correctly classified, compared with 74 (61\%) correctly classified children with the API alone. The addition of VOCs data significantly improved the area under the receiver operating characteristic curve (AUC) from 61 (95\% CI: 52-69) with 
the API alone to 89 (95\% CI: 83-95) $(p<0.0001) .{ }^{23}$ Likewise, Smolinska et al analyzed the total array of exhaled VOCs of 252 children between 2 and 4 years of age with recurrent wheezing symptoms and identified a set of 17 VOCs that allowed distinguishing children with transient wheeze from true asthmatics, with a correct prediction rate of $80 \%$ in an independent test set. ${ }^{38}$ Finally, Caudri et al determined that higher FeNO values in 4-year-old children with asthmasuggestive symptoms were a significant predictor of asthma symptoms up to the age of 8 years, independent of clinical history $(\mathrm{OR}=1.6 ; 95 \% \mathrm{CI}: 1.1-2.2)^{28}$ (Figure 4).

\section{Ethnicity}

In the TCRS, Hispanic ethnicity was identified as an independent predictor of wheezing persistence at the age of 6 years among those children with recurrent wheezing during the first 3 years of life $(\mathrm{OR}=3.0 ; 95 \% \mathrm{CI}: 1.6-5.5){ }^{7}$

\section{Gene expression}

Klaassen et al reported that by adding data for three gene expression markers (toll-like receptor 4, catalase, and tumor necrosis factor) to the API, 77 (74\%) of the 122 children included in the discovery set were correctly classified compared with $60(58 \%)$ children correctly classified with the API alone. The addition of gene expression data significantly improved the AUC from 58 (95\% CI: 48-67) with the API alone to 75 (95\% CI: 66-85) $(p=0.001){ }^{23}$

\section{Delivery}

Post-term delivery ( $>42$ weeks) was an independent predictor of asthma at 7-8 years of age in the PIAMA birth cohort study $(\mathrm{OR}=2.1 ; 95 \% \mathrm{CI}: 1.2-3.6)$, and was one of the eight clinical parameters that composed the PIAMA risk score, resulting in 7.3 of a total of 55.1 points in the prediction score. ${ }^{24}$ In the modified version of the PIAMA risk score, post-term delivery was also included as one of the eight clinical parameters considered important for predicting persistent asthma at the age of 6 years. ${ }^{10}$

\section{Parental education}

Medium/low parental education (defined as an education less than the level of a bachelor's/master's degree - HBO/University in Dutch system - for at least one of the parents) was an independent predictor of asthma at 7-8 years of age in the PIAMA birth cohort study $(\mathrm{OR}=1.5 ; 95 \% \mathrm{CI}: 1.1-2.2)$, and was one of the eight clinical parameters that composed the PIAMA risk score, resulting in 4.2 of a total of 55.1 points in the prediction score. ${ }^{24}$ Likewise, in the modified version of the PIAMA risk score, medium/low parental education was also included as one of the eight clinical parameters considered important for predicting persistent asthma at the age of 6 years. ${ }^{10}$

\section{Parental inhalation medication}

Parental inhalation medication use (defined as inhalation medication use by at least one parent) was an independent predictor of asthma at 7-8 years of age in the PIAMA birth cohort study $(\mathrm{OR}=2.2 ; 95 \% \mathrm{CI}: 1.6-3.0)$, and was one of the eight clinical parameters that composed the risk score, accounting for 7.7 of a total of 55.1 points in the prediction score. ${ }^{24}$

\section{Number of siblings}

Infants with three or more siblings and had recurrent wheezing during the first year of life had significantly less risk of having asthma symptoms at the age of 6 years in the cohort study reported by Just et al (OR=0.36; 95\% CI: $0.17-0.76$; $p=0.008) .^{13}$

\section{Parental smoking}

Maternal smoking was an independent predictor of asthma at 6 years of age in the TCRS (OR=2.3; 95\% CI: $1.2-4.4){ }^{7}$ Likewise, Csonka et al established that exposure to passive smoke when $<3$ years of age was independently associated with symptom persistence up to school age (OR=2.1; $95 \%$ CI: $1.2-3.7 ; p=0.008){ }^{20}$

\section{Contact with/exposure to animals in early life}

Presence of pets in the home during the first year of life was identified as an independent protector factor for asthma persistence at the age of 6 years $(\mathrm{OR}=0.32 ; 95 \% \mathrm{CI}$ : $0.16-0.63 ; p=0.001) .{ }^{13}$ Likewise, a furry pet in the home in early childhood was an independent protector factor for persistence of asthma at the age of 4 years $(O R=0.30 ; 95 \%$ CI: $0.10-0.79 ; p=0.016) .{ }^{27}$

\section{Age at presentation}

Clough et al, in a prospective study to determine which factors might be predictive of the persistence of wheeze (disease requiring treatment that persists for at least 12 months after presentation) among 107 children aged 3-36 months with at least one atopic parent and recent onset (in the previous 12 weeks) of wheeze (either one major episode lasting at least 24 hours or three minor episodes lasting at least 6 hours), found that the model offering the best prediction with the least risk of including asymptomatic subjects revealed that wheeze was more likely to be persistent in older children (age in months; $\mathrm{OR}=1.0699 ; p=0.0158) .{ }^{39}$ Also, age (years) was positively correlated with a greater probability of asthma at the age of 6 years in the multivariable analysis in the Airway Complaints 
and Asthma Development (ARCADE) study (OR=1.47; 95\% CI: $1.24-1.75 ; p<0.001) .{ }^{17}$ Age $>1$ year was one of the ten predictor variables included in the tool proposed by Pescatore et al. ${ }^{18}$ Likewise, Reijonen et al identified age $\geq 12$ months on entry as an independent predictor of asthma at the median age of 4 years $(\mathrm{OR}=4.1 ; 95 \%$ CI: $1.59-10.35 ; p=0.0034) .{ }^{27}$

\section{Creola bodies}

Yamada et al, in 23 wheezing infants, reported that those with Creola bodies (clusters of ciliated columnar cells sloughed from the bronchial mucosa) in their sputum were significantly more likely ( $80 \%$ vs. $0 \%, p<0.001)$ to be diagnosed with infantile asthma during the following 2-year period than those without Creola bodies. ${ }^{40}$

\section{Etiology of early wheezing episodes}

Respiratory syncytial virus identification on entry and viral identification on entry were identified as independent protector factors for persistence of asthma at the age of 4 years $(\mathrm{OR}=0.30 ; 95 \% \mathrm{CI}: 0.08-0.80 ; p=0.019$, and $\mathrm{OR}=0.40 ; 95 \%$ CI: $0.15-1.01 ; p=0.051$, respectively). ${ }^{27}$

\section{Recurrent abdominal pain}

Recurrent abdominal pain (probably caused by food hypersensitivity and food allergy, although other causes such as gastroesophageal reflux disease or constipation could not be excluded) was identified as an independent predictor of active asthma at 8 years of age in a prospective population-based birth cohort $(\mathrm{OR}=2.33 ; 95 \% \mathrm{CI}: 1.30-4.16){ }^{21}$

\section{Discussion}

In a comprehensive literature review of exclusively longitudinal cohort studies performed in children under the age of 5 years with recurrent wheezing, we found that parental asthma (especially maternal), parental allergy, eczema, allergic rhinitis, persistent wheezing (especially three or more episodes), wheeze without cold, exercise-induced wheeze, a severe wheezing episode, allergic sensitization (especially polysensitization), eosinophils (blood or endothelial progenitor cells [EPCs] in nasal sample), FeNO, age of onset $\geq 12$ months, and male gender were risk factors that significantly predicted asthma during the elementary school and adolescent periods. Among all the identified predictors, the most frequently identified ones were the following: family asthma or atopy; personal history of atopic diseases; allergic sensitization early in life; and frequency, clinical pattern, or severity of wheezing/symptoms.

Clearly, most of these factors are involved in the existing algorithms built to predict asthma in children (e.g. API and the mAPIs). Therefore, these findings reaffirm the utility of these algorithms for predicting asthma. Of course, taking into consideration only one parameter for predicting future asthma in preschoolers with recurrent wheezing episodes will be less useful than using a score or algorithm. Indeed, while choosing one algorithm, it is better to consider the one with the highest positive LR and the lowest negative LR. In this respect, the algorithm with the highest positive LR is the mAPI proposed by Klaassen et al, ${ }^{23}$ with 8.9 , followed by the Isle of Wight with 7.9, ${ }^{11}$ modified ucAPI with 7.8, and original API with 7.4. ${ }^{3}$ However, the original $\mathrm{API}^{3}$ is the only algorithm that at the moment fulfills all the clinical prediction rules ${ }^{41}$ (e.g. development, ${ }^{3}$ validation/updating, ${ }^{24,29,42}$ impact, ${ }^{43-46}$ and implementations $s^{47-50}$ ).

The highest OR found for an individual risk factor was for maternal asthma, ${ }^{7,16}$ and as was expected, the risk factor increases when many diseases are combined (e.g. parental atopies including allergic rhinitis, asthma, and dermatitis). ${ }^{12}$ Among personal antecedents, eczema and allergic rhinitis were the highest risk factors. ${ }^{10,25}$ Allergic sensitization, especially polysensitization to indoor allergens, ${ }^{12,16,27}$ was a risk factor related to asthma development.

However, it is important to be aware that the definition of allergic sensitization was arbitrary, and it remains unclear as to how allergen sensitization in toto contributes to the clinical manifestation of different atopic diseases, including asthma. Prosperi et al, using new statistical methods such as random forests and Bayesian networks, demonstrated in 288 children that specific IgE to dust mite, pollens, and a pet allergen was highly associated with asthma. ${ }^{51}$ Simpson et al, working with the same group of children, using latent variable modeling in 221 participants with a positive IgE to one or more components, showed that 61 allergen components clustered into three component groups, and that sensitization to one component that includes 27 components of plants, animals, and fungi, were strongly associated with asthma $(\mathrm{OR}=8.20$; 95\% CI: $3.49-19.24 ; p<0.001)$ and lower volume exhaled during the first second (forced expiratory volume in $1 \mathrm{sec}-$ ond). ${ }^{52}$ Finally, age and sex should be taken into account when interpreting the results of SPT and specific IgE measurement, and age- and sex-specific normative data are needed for these allergic tests. ${ }^{53}$ That could mean that all of those algorithms for predicting asthma that include specific IgE or SPT, for example, all the mAPIs, had this problem. ${ }^{8,9,23}$

In contrast, apparently by using blood eosinophils count as a risk factor for asthma, there is no need of that kind of adjustment, showing that eosinophils count could be a cheaper and better biomarker for allergy among those recurrent-wheezing preschoolers who have a risk of asthma 
development at school age, as was incorporated in the API. However, when another marker of eosinophilic imflamation, for example, FeNO, was added to the original API, as in the study by Singer et al, the LR did not significantly improve ${ }^{37}$ For all the above-mentioned reasons, we think that the original API, which only uses eosinophils count as one minor criterion, would be more useful than those algorithms that include other atopic markers (e.g. specific IgE, SPT, or FeNO).

The only biomarkers that seem to improve the original API were VOCs and genetic polymorphisms. In the algorithm developed by Klaassen et al, ${ }^{23}$ adding those markers to the API algorithm increased the positive LR to 8.9, compared with the 7.4 that the original API had. However, since those markers are expensive, sophisticated, and complicated to implement even in every tertiary health service, their routine use is precluded in a primary health setting, in contrast to the original API.

Other risk factors such as Creola bodies ${ }^{40}$ have not been replicated in other longitudinal studies. Regarding gender, it is important to take into consideration that male gender was a risk factor for asthma up to school age. However, it is well known that the situation will be the reverse in the adolescent period, where females suffer from a higher rate of asthma than males. Therefore, we think that gender will not be truly asthma-predictive. The onset of wheezing after 12 months of age is a risk factor for asthma, since it is well known that under the age of 12 months, other phenotypes of asthma can coexist (e.g. transient wheezers). Other factors, such as type of delivery, breastfeeding, parental education, number of siblings, smoking, pets, and respiratory infections, are environmental risk factors for asthma included in a few, but not all, predictive scores, which could vary according to the particular locale. An expansive report using meta-analysis has recently been published by our group. ${ }^{54}$

This study has limitations that merit being taken into account. First, the literature search may have been incomplete because we did not include gray literature, unpublished work, or dissertations. However, we consider that the identified studies include the most significant and consistent predictors of early wheezing through childhood and adolescence and are useful for this purpose. Second, although the great majority of included studies performed multivariate analyses in order to identify factors predicting persistence of early wheezing throughout childhood and adolescence, as is the case for other observational epidemiologic studies, residual confounding cannot be excluded, so interpretation of the results needs to be done with caution.
In conclusion, parental asthma (especially maternal), parental allergy, eczema, allergic rhinitis, persistent wheezing, wheeze without colds, exercise-induced wheeze, severe wheezing episodes, allergic sensitization (especially polysensitization), eosinophils (blood or EPCs in nasal sample), and FeNO are risk factors predicting persistence of early wheezing through school age. All of them are included in conventional algorithms, for example, API and its modifications, for predicting future occurrence of asthma.

\section{Acknowledgment}

The authors thank Mr Charlie Barrett for his editorial assistance.

\section{Disclosure}

The authors report no conflicts of interest in this work.

\section{References}

1. Graham LM. Preschool wheeze prognosis: how do we predict outcome? Paediatr Respir Rev. 2006;7 Suppl 1:S115-S116.

2. Hancox RJ, Subbarao P, Sears MR. Relevance of birth cohorts to assessment of asthma persistence. Curr Allergy Asthma Rep. 2012;12(3): 175-184.

3. Castro-Rodriguez JA, Holberg CJ, Wright AL, Martinez FD. A clinical index to define risk of asthma in young children with recurrent wheezing. Am J Respir Crit Care Med. 2000;162(4 Pt 1):1403-1406.

4. Savenije OE, Kerkhof M, Koppelman GH, Postma DS. Predicting who will have asthma at school age among preschool children. J Allergy Clin Immunol. 2012;130(2):325-331.

5. Matricardi PM, Illi S, Keil T, Wagner P, Wahn U, Lau S. Predicting persistence of wheezing: one algorithm does not fit all. Eur Respir J. 2010; 35(3):701-703.

6. von Elm E, Altman DG, Egger M, Pocock SJ, Gøtzsche PC, Vandenbroucke JP; STROBE Initiative. The Strengthening the Reporting of Observational Studies in Epidemiology (STROBE) statement: guidelines for reporting observational studies. Lancet. 2007;370(9596): $1453-1457$

7. Martinez FD, Wright AL, Taussig LM, Holberg CJ, Halonen M, Morgan WJ. Asthma and wheezing in the first six years of life. The Group Health Medical Associates. N Engl J Med. 1995;332(3):133-138.

8. Guilbert TW, Morgan WJ, Krawiec M, et al; Prevention of Early Asthma in Kids Study, Childhood Asthma Research and Education Network. The Prevention of Early Asthma in Kids study: design, rationale and methods for the Childhood Asthma Research and Education network. Control Clin Trials. 2004;25(3):286-310.

9. Amin P, Levin L, Epstein T, et al. Optimum predictors of childhood asthma: persistent wheeze or the Asthma Predictive Index? J Allergy Clin Immunol Pract. 2014;2(6):709-715.

10. Hafkamp-de Groen E, Lingsma HF, Caudri D, et al. Predicting asthma in preschool children with asthma-like symptoms: validating and updating the PIAMA risk score. J Allergy Clin Immunol. 2013;132(6): 1303-1310.

11. Kurukulaaratchy RJ, Matthews S, Holgate ST, Arshad SH. Predicting persistent disease among children who wheeze during early life. Eur Respir J. 2003;22(5):767-771.

12. Matricardi PM, Illi S, Grüber C, et al. Wheezing in childhood: incidence, longitudinal patterns and factors predicting persistence. Eur Respir J. 2008;32(3):585-592.

13. Just J, Belfar S, Wanin S, Pribil C, Grimfeld A, Duru G. Impact of innate and environmental factors on wheezing persistence during childhood. J Asthma. 2010;47(4):412-416. 
14. Henderson J, Granell R, Heron J, et al. Associations of wheezing phenotypes in the first 6 years of life with atopy, lung function and airway responsiveness in mid-childhood. Thorax. 2008;63(11):974-980.

15. Caudri D, Savenije OE, Smit HA, et al. Perinatal risk factors for wheezing phenotypes in the first 8 years of life. Clin Exp Allergy. 2013; 43(12):1395-1405.

16. Vial Dupuy A, Amat F, Pereira B, Labbe A, Just J. A simple tool to identify infants at high risk of mild to severe childhood asthma: the persistent asthma predictive score. JAsthma. 2011;48(10):1015-1021.

17. van der Mark LB, van Wonderen KE, Mohrs J, van Aalderen WM, ter Riet G, Bindels PJ. Predicting asthma in preschool children at high risk presenting in primary care: development of a clinical asthma prediction score. Prim Care Respir J. 2014;23(1):52-59.

18. Pescatore AM, Dogaru CM, Duembgen L, et al. A simple asthma prediction tool for preschool children with wheeze or cough. J Allergy Clin Immunol. 2014;133(1):111-118.e1-13.

19. Mikalsen IB, Halvorsen T, Eide GE, Oymar K. Severe bronchiolitis in infancy: can asthma in adolescence be predicted? Pediatr Pulmonol. 2013;48(6):538-544.

20. Csonka P, Kaila M, Laippala P, Kuusela AL, Ashorn P. Wheezing in early life and asthma at school age: predictors of symptom persistence. Pediatr Allergy Immunol. 2000;11(4):225-229.

21. Neuman A, Bergstrom A, Gustafsson P, et al. Infant wheeze, comorbidities and school age asthma. Pediatr Allergy Immunol. 2014;25(4): 380-386.

22. Chang TS, Lemanske RF Jr, Guilbert TW, et al. Evaluation of the modified asthma predictive index in high-risk preschool children. J Allergy Clin Immunol Pract. 2013;1(2):152-156.

23. Klaassen EM, van de Kant KD, Jöbsis Q, et al. Exhaled biomarkers and gene expression at preschool age improve asthma prediction at 6 years of age. Am J Respir Crit Care Med. 2015;191(2):201-207.

24. Caudri D, Wijga A, A Schipper CM, et al. Predicting the long-term prognosis of children with symptoms suggestive of asthma at preschool age. J Allergy Clin Immunol. 2009;124(5):903-910.e1-7.

25. Frank PI, Morris JA, Hazell ML, Linehan MF, Frank TL. Long term prognosis in preschool children with wheeze: longitudinal postal questionnaire study 1993-2004. BMJ. 2008;336(7658):1423-1426.

26. Amat F, Vial A, Pereira B, Petit I, Labbe A, Just J. Predicting the longterm course of asthma in wheezing infants is still a challenge. ISRN Allergy. 2011;2011:493624.

27. Reijonen TM, Kotaniemi-Syrjanen A, Korhonen K, Korppi M. Predictors of asthma three years after hospital admission for wheezing in infancy. Pediatrics. 2000;106(6):1406-1412.

28. Caudri D, Wijga AH, Hoekstra MO, et al. Prediction of asthma in symptomatic preschool children using exhaled nitric oxide, Rint and specific IgE. Thorax. 2010;65(9):801-807.

29. Leonardi NA, Spycher BD, Strippoli MP, Frey U, Silverman M, Kuehni CE. Validation of the Asthma Predictive Index and comparison with simpler clinical prediction rules. J Allergy Clin Immunol 2011;127(6):1466-1472.e6.

30. Devulapalli CS, Carlsen KC, Håland G, et al. Severity of obstructive airways disease by age 2 years predicts asthma at 10 years of age. Thorax. 2008;63(1):8-13.

31. To T, Gershon A, Wang C, Dell S, Cicutto L. Persistence and remission in childhood asthma: a population-based asthma birth cohort study. Arch Pediatr Adolesc Med. 2007;161(12):1197-1204.

32. Hyvarinen MK, Kotaniemi-Syrjänen A, Reijonen TM, PiippoSavolainen E, Korppi M. Eosinophil activity in infants hospitalized for wheezing and risk of persistent childhood asthma. Pediatr Allergy Immunol. 2010;21(1 Pt 1):96-103.

33. Sherrill DL, Stein R, Halonen M, Holberg CJ, Wright A, Martinez FD. Total serum IgE and its association with asthma symptoms and allergic sensitization among children. J Allergy Clin Immunol. 1999; 104(1):28-36.

34. Oostveen E, Dom S, Desager K, Hagendorens M, De Backer W, Weyler J. Lung function and bronchodilator response in 4-year-old children with different wheezing phenotypes. Eur Respir J. 2010;35(4):865-872.
35. Turner SW, Palmer LJ, Rye PJ, et al. The relationship between infant airway function, childhood airway responsiveness, and asthma. Am J Respir Crit Care Med. 2004;169(8):921-927.

36. Delacourt C, Benoist MR, Waernessyckle S, et al. Relationship between bronchial responsiveness and clinical evolution in infants who wheeze: a four-year prospective study. Am J Respir Crit Care Med. 2001;164(8 Pt 1):1382-1386.

37. Singer F, Luchsinger I, Inci D, et al. Exhaled nitric oxide in symptomatic children at preschool age predicts later asthma. Allergy. 2013; 68(4):531-538.

38. Smolinska A, Klaassen EM, Dallinga JW, et al. Profiling of volatile organic compounds in exhaled breath as a strategy to find early predictive signatures of asthma in children. PLoS One. 2014;9(4):e95668.

39. Clough JB, Keeping KA, Edwards LC, Freeman WM, Warner JA, Warner JO. Can we predict which wheezy infants will continue to wheeze? Am J Respir Crit Care Med. 1999;160(5 Pt 1):1473-1480.

40. Yamada Y, Yoshihara S, Arisaka O. Creola bodies in wheezing infants predict the development of asthma. Pediatr Allergy Immunol. 2004; 15(2):159-162.

41. Toll DB, Janssen KJ, Vergouwe Y, Moons KG. Validation, updating and impact of clinical prediction rules: a review. J Clin Epidemiol. 2008; 61(11):1085-1094.

42. Rodriguez-Martinez CE, Sossa-Briceno MP, Castro-Rodriguez JA. Discriminative properties of two predictive indices for asthma diagnosis in a sample of preschoolers with recurrent wheezing. Pediatr Pulmonol. 2011;46(12):1175-1181.

43. Balinotti JE, Colom A, Kofman C, Teper A. Association between the Asthma Predictive Index and levels of exhaled nitric oxide in infants and toddlers with recurrent wheezing. Arch Argent Pediatr. 2013; 111(3):191-195.

44. Berankova K, Uhlik J, Honkova L, Pohunek P. Structural changes in the bronchial mucosa of young children at risk of developing asthma. Pediatr Allergy Immunol. 2014;25(2):136-142.

45. Castro-Rodriguez JA, Sardón O, Pérez-Yarza EG, et al. Young infants with recurrent wheezing and positive asthma predictive index have higher levels of exhaled nitric oxide. J Asthma. 2013;50(2):162-165.

46. Keklikian E, Sanchez-Solis M, Bonina AJ, et al. Do risk factors for persistent asthma modify lung function in infants and young children with recurrent wheeze? Pediatr Pulmonol. 2010;45(9):914-918.

47. Brand PL, Luz Garcia-Garcia M, Morison A, Vermeulen JH, Weber HC. Ciclesonide in wheezy preschool children with a positive asthma predictive index or atopy. Respir Med. 2011;105(11):1588-1595.

48. Li YQ, Xue HY, Chen W, Cao LF. [Application of asthma predictive index-based group therapy in wheezing children under 5 years of age]. Zhongguo Dang Dai Er Ke Za Zhi. 2014;16(8):795-799. Chinese [with English abstract].

49. Expert panel, National Asthma Education and Prevention Program. Guidelines for the diagnosis and management of asthma. 2007 [updated 2008]. Available from: www.nhlbi.nih.gov/guidelines/asthma/asthgdln. htm. Accesed November 7, 2016.

50. Global Initiative for Asthma. Global strategy for asthma management and prevention. 2015. Available from: http://ginasthma.org/wp-content/ uploads/2016/01/GINA_Report_2015_Aug11-1.pdf. Accessed March 4, 2017.

51. Prosperi MC, Belgrave D, Buchan I, Simpson A, Custovic A. Challenges in interpreting allergen microarrays in relation to clinical symptoms: a machine learning approach. Pediatr Allergy Immunol. 2014;25(1): 71-79.

52. Simpson A, Lazic N, Belgrave DC, et al. Patterns of IgE responses to multiple allergen components and clinical symptoms at age 11 years. J Allergy Clin Immunol. 2015;136(5):1224-1231.

53. Mohammad HR, Belgrave D, Kopec Harding K, Murray CS, Simpson A, Custovic A. Age, sex and the association between skin test responses and IgE titres with asthma. Pediatr Allergy Immunol. 2016;27(3):313-319.

54. Castro-Rodriguez JA, Forno E, Rodriguez-Martinez CE, Celedon JC. Risk and protective factors for childhood asthma: what is the evidence? J Allergy Clin Immunol Pract. 2016;4(6):1111-1122. 


\section{Supplementary material}

Table SI List of strobe item ratings per study

\begin{tabular}{|c|c|c|c|c|c|c|c|c|c|c|c|c|}
\hline \multirow[t]{2}{*}{ Strobe items } & \multicolumn{12}{|c|}{ References } \\
\hline & $\mathbf{I}$ & 2 & 3 & 4 & 5 & 6 & 7 & 8 & 9 & 10 & II & 12 \\
\hline Ia Indicate the design with a commonly used term & $\mathrm{Y}$ & $Y$ & Y & $Y$ & Y & $Y$ & Y & Y & Y & Y & $\mathrm{Y}$ & Y \\
\hline Ib In abstract provide an informative summary & Y & Y & Y & Y & Y & $\mathrm{Y}$ & Y & Y & Y & Y & Y & Y \\
\hline 2 Explain the scientific background and rationale & $Y$ & Y & $Y$ & $\mathrm{Y}$ & Y & Y & Y & $\mathrm{Y}$ & Y & Y & $Y$ & Y \\
\hline 3 State specific objectives and hypotheses & Y & Y & Y & Y & Y & Y & Y & Y & Y & Y & Y & Y \\
\hline 4 Present key elements of study design & Y & Y & Y & Y & Y & Y & Y & Y & Y & Y & Y & Y \\
\hline 5 Describe the settings, locations, and relevant dates & $Y$ & Y & $\mathrm{Y}$ & Y & Y & Y & Y & Y & Y & Y & $Y$ & Y \\
\hline 6a Give the eligibility criteria & Y & Y & Y & Y & Y & Y & Y & Y & Y & Y & Y & Y \\
\hline 6b For matched studies, gives matching criteria & N/A & $\mathrm{N} / \mathrm{A}$ & $\mathrm{N} / \mathrm{A}$ & $\mathrm{N} / \mathrm{A}$ & $\mathrm{N} / \mathrm{A}$ & $\mathrm{N} / \mathrm{A}$ & $\mathrm{N} / \mathrm{A}$ & $\mathrm{N} / \mathrm{A}$ & $\mathrm{N} / \mathrm{A}$ & N/A & $\mathrm{N} / \mathrm{A}$ & $\mathrm{N} / \mathrm{A}$ \\
\hline 7 Define outcomes, exposures, and confounders & Y & Y & Y & Y & Y & Y & Y & Y & Y & Y & Y & Y \\
\hline 8 For each variable, sources of data and assessment method & $\mathrm{Y}$ & Y & $\mathrm{Y}$ & Y & Y & Y & Y & Y & Y & Y & $\mathrm{Y}$ & $\mathrm{N}$ \\
\hline 9 Describe any efforts to address potential sources of bias & Y & Y & $\mathrm{N}$ & Y & Y & Y & Y & Y & Y & Y & $\mathrm{N}$ & Y \\
\hline 10 Explain how the study size was arrived at & $\mathrm{N}$ & $\mathrm{N}$ & $\mathrm{N}$ & $\mathrm{N}$ & $\mathrm{N}$ & $\mathrm{N}$ & $\mathrm{N}$ & $\mathrm{N}$ & $\mathrm{N}$ & $\mathrm{N}$ & $\mathrm{N}$ & $\mathrm{N}$ \\
\hline II Explain how variables were handled in analyses & $\mathrm{Y}$ & Y & $\mathrm{Y}$ & Y & $\mathrm{Y}$ & $\mathrm{Y}$ & Y & $\mathrm{Y}$ & $\mathrm{Y}$ & $\mathrm{Y}$ & $\mathrm{Y}$ & Y \\
\hline 12a Describe all statistical methods & $\mathrm{Y}$ & Y & $\mathrm{Y}$ & Y & Y & Y & Y & Y & Y & $\mathrm{Y}$ & Y & Y \\
\hline I $2 \mathrm{~b}$ Describe methods to examine interactions & $\mathrm{N}$ & $\mathrm{N}$ & $\mathrm{N}$ & Y & Y & $\mathrm{Y}$ & $\mathrm{N}$ & $\mathrm{Y}$ & Y & $\mathrm{N}$ & $\mathrm{Y}$ & $\mathrm{N}$ \\
\hline 12c Explain how missing data were addressed & Y & $\mathrm{N}$ & $\mathrm{N}$ & Y & Y & Y & $\mathrm{N}$ & Y & Y & $\mathrm{N}$ & Y & Y \\
\hline 12d Explain how loss to follow-up was addressed & Y & Y & $\mathrm{N}$ & Y & Y & Y & $\mathrm{N}$ & Y & Y & Y & Y & $\mathrm{N}$ \\
\hline 12e Describe any sensitivity analyses & Y & Y & Y & Y & Y & $\mathrm{N}$ & $\mathrm{N}$ & Y & Y & $\mathrm{N}$ & Y & Y \\
\hline I3a Report number of individuals at each stage of study & $\mathrm{Y}$ & Y & $\mathrm{Y}$ & Y & Y & Y & Y & Y & Y & $\mathrm{Y}$ & Y & Y \\
\hline I3b Give reasons for nonparticipation at each stage & $\mathrm{Y}$ & Y & $\mathrm{N}$ & Y & Y & $\mathrm{Y}$ & $\mathrm{N}$ & $\mathrm{Y}$ & Y & $Y$ & Y & $\mathrm{N}$ \\
\hline I3c Consider use of a flow diagram & $\mathrm{N}$ & $\mathrm{N}$ & $\mathrm{N}$ & $\mathrm{N}$ & $\mathrm{N}$ & Y & $\mathrm{N}$ & $\mathrm{N}$ & Y & $\mathrm{N}$ & Y & $\mathrm{N}$ \\
\hline 14a Give characteristic of study participants & Y & Y & Y & Y & Y & Y & Y & Y & Y & Y & Y & Y \\
\hline 14b Indicate number of participants with missing data & Y & Y & $\mathrm{Y}$ & Y & Y & Y & Y & Y & Y & Y & Y & Y \\
\hline 14c Summarize follow-up time & Y & Y & Y & Y & Y & Y & Y & Y & Y & Y & Y & Y \\
\hline I5 Report numbers of outcome events & Y & Y & Y & Y & Y & Y & Y & Y & Y & Y & Y & Y \\
\hline I6a Give unadjusted estimates & Y & Y & $\mathrm{Y}$ & Y & Y & Y & Y & Y & Y & Y & Y & Y \\
\hline I6b Report category boundaries & Y & Y & Y & Y & Y & Y & Y & Y & Y & Y & Y & Y \\
\hline 16c Consider translating estimates of relative risk & N/A & N/A & N/A & N/A & $\mathrm{N} / \mathrm{A}$ & N/A & $\mathrm{N} / \mathrm{A}$ & $\mathrm{N} / \mathrm{A}$ & N/A & N/A & Y & $\mathrm{N} / \mathrm{A}$ \\
\hline 17 Report other analyses done & Y & Y & Y & Y & Y & Y & Y & Y & Y & Y & Y & $\mathrm{Y}$ \\
\hline I8 Summarize key results & Y & Y & Y & Y & Y & Y & Y & Y & Y & Y & Y & Y \\
\hline 19 Discuss limitations and potential bias & Y & Y & Y & Y & $\mathrm{N}$ & Y & Y & Y & Y & Y & Y & Y \\
\hline 20 Give a cautious overall interpretation of results & $\mathrm{Y}$ & Y & Y & Y & Y & Y & Y & Y & Y & Y & $\mathrm{Y}$ & $\mathrm{N}$ \\
\hline 2I Discuss the generalizability & Y & $\mathrm{N}$ & $\mathrm{Y}$ & $\mathrm{Y}$ & $\mathrm{N}$ & $\mathrm{Y}$ & Y & $\mathrm{Y}$ & Y & Y & Y & Y \\
\hline 22 Give the source of funding & Y & $\mathrm{Y}$ & $Y$ & Y & Y & Y & Y & Y & Y & $\mathrm{N}$ & Y & $Y$ \\
\hline
\end{tabular}

Abbreviations: N/A, not applicable; N, No; Y, Yes.

\section{References}

1. Castro-Rodriguez JA, Holberg CJ, Wright AL, Martinez FD. A clinical index to define risk of asthma in young children with recurrent wheezing. Am J Respir Crit Care Med. 2000;162(4 Pt 1):1403-1406.

2. Martinez FD, Wright AL, Taussig LM, Holberg CJ, Halonen M, Morgan WJ. Asthma and wheezing in the first six years of life. The Group Health Medical Associates. NEngl J Med. 1995;332(3):133-138.

3. Amin P, Levin L, Epstein T, et al. Optimum predictors of childhood asthma: persistent wheeze or the Asthma Predictive Index? J Allergy Clin Immunol Pract. 2014;2(6):709-715.

4. Hafkamp-de Groen E, Lingsma HF, Caudri D, et al. Predicting asthma in preschool children with asthma-like symptoms: validating and updating the PIAMA risk score. J Allergy Clin Immunol. 2013;132(6):1303-1310.

5. Kurukulaaratchy RJ, Matthews S, Holgate ST, Arshad SH. Predicting persistent disease among children who wheeze during early life. Eur Respir J. 2003;22(5):767-771.

6. Matricardi PM, Illi S, Grüber C, et al. Wheezing in childhood: incidence, longitudinal patterns and factors predicting persistence. Eur Respir J. 2008;32(3):585-592.
7. Just J, Belfar S, Wanin S, Pribil C, Grimfeld A, Duru G. Impact of innate and environmental factors on wheezing persistence during childhood. J Asthma. 2010;47(4):412-416.

8. Henderson J, Granell R, Heron J, et al. Associations of wheezing phenotypes in the first 6 years of life with atopy, lung function and airway responsiveness in mid-childhood. Thorax. 2008;63(11):974-980.

9. Caudri D, Savenije OE, Smit HA, et al. Perinatal risk factors for wheezing phenotypes in the first 8 years of life. Clin Exp Allergy. 2013;43(12):1395-1405.

10. Vial Dupuy A, Amat F, Pereira B, Labbe A, Just J. A simple tool to identify infants at high risk of mild to severe childhood asthma: the persistent asthma predictive score. J Asthma. 2011;48(10): 1015-1021.

11. van der Mark LB, van Wonderen KE, Mohrs J, van Aalderen WM, ter Riet G, Bindels PJ. Predicting asthma in preschool children at high risk presenting in primary care: development of a clinical asthma prediction score. Prim Care Respir J. 2014;23(1):52-59.

12. Pescatore AM, Dogaru CM, Duembgen L, et al. A simple asthma prediction tool for preschool children with wheeze or cough. JAllergy Clin Immunol. 2014;133(1):111-118.e1-13. 


\begin{tabular}{|c|c|c|c|c|c|c|c|c|c|c|c|c|c|c|c|c|c|c|c|c|c|}
\hline 13 & 14 & 15 & 16 & 17 & 18 & 19 & 20 & 21 & 22 & 23 & 24 & 25 & 26 & 27 & 28 & 29 & 30 & 31 & 32 & 33 & 34 \\
\hline $\mathrm{N}$ & $Y$ & $Y$ & $Y$ & $\mathrm{~N}$ & $Y$ & $Y$ & $\mathrm{~N}$ & $Y$ & $Y$ & $Y$ & $Y$ & $Y$ & $N$ & $\mathrm{~N}$ & $Y$ & $Y$ & $Y$ & $N$ & $\mathrm{~N}$ & $Y$ & $\mathrm{~N}$ \\
\hline Y & $Y$ & $Y$ & $Y$ & $Y$ & $Y$ & $Y$ & $Y$ & $Y$ & $Y$ & $Y$ & $Y$ & $Y$ & $Y$ & $Y$ & $Y$ & $Y$ & $Y$ & $Y$ & $Y$ & $Y$ & $Y$ \\
\hline Y & $Y$ & $Y$ & $Y$ & $Y$ & $Y$ & $Y$ & $Y$ & $Y$ & $Y$ & $Y$ & $Y$ & $Y$ & $Y$ & $Y$ & $Y$ & $Y$ & $Y$ & $Y$ & $Y$ & $Y$ & $Y$ \\
\hline Y & $Y$ & $Y$ & $Y$ & $Y$ & $Y$ & $Y$ & $Y$ & $Y$ & $Y$ & $Y$ & $Y$ & $Y$ & $Y$ & $Y$ & $Y$ & $Y$ & Y & $Y$ & $Y$ & $Y$ & $Y$ \\
\hline Y & $Y$ & $Y$ & $Y$ & $Y$ & $Y$ & $Y$ & $Y$ & $Y$ & Y & $Y$ & $Y$ & $Y$ & $Y$ & $Y$ & $Y$ & $Y$ & $Y$ & $Y$ & $Y$ & $Y$ & Y \\
\hline$Y$ & $N$ & $Y$ & $Y$ & $\mathrm{~N}$ & $Y$ & $Y$ & $Y$ & $Y$ & $Y$ & $Y$ & $Y$ & $Y$ & $Y$ & $Y$ & $Y$ & $Y$ & $Y$ & $Y$ & $Y$ & $Y$ & $Y$ \\
\hline Y & $Y$ & $Y$ & $Y$ & $Y$ & Y & $Y$ & $Y$ & $Y$ & Y & $Y$ & $Y$ & $Y$ & $Y$ & $Y$ & $Y$ & $\mathrm{Y}$ & $Y$ & $Y$ & $Y$ & $Y$ & $Y$ \\
\hline$N / A$ & $\mathrm{~N} / \mathrm{A}$ & $\mathrm{N} / \mathrm{A}$ & $\mathrm{N} / \mathrm{A}$ & $\mathrm{N} / \mathrm{A}$ & $\mathrm{N} / \mathrm{A}$ & N/A & $\mathrm{N} / \mathrm{A}$ & $\mathrm{N} / \mathrm{A}$ & $\mathrm{N} / \mathrm{A}$ & $\mathrm{N} / \mathrm{A}$ & $Y$ & $\mathrm{~N} / \mathrm{A}$ & $\mathrm{N} / \mathrm{A}$ & $\mathrm{N} / \mathrm{A}$ & $\mathrm{N} / \mathrm{A}$ & $\mathrm{N} / \mathrm{A}$ & $\mathrm{N} / \mathrm{A}$ & $\mathrm{N} / \mathrm{A}$ & N/A & $\mathrm{N} / \mathrm{A}$ & $\mathrm{N} / \mathrm{A}$ \\
\hline Y & $Y$ & $Y$ & $Y$ & $Y$ & $Y$ & $Y$ & $Y$ & $Y$ & $Y$ & $Y$ & $Y$ & $Y$ & $Y$ & $Y$ & $\mathrm{~N}$ & $Y$ & $Y$ & $Y$ & $\mathrm{~N}$ & $Y$ & $Y$ \\
\hline$N$ & $Y$ & $Y$ & $Y$ & $Y$ & $Y$ & $Y$ & $Y$ & $Y$ & $Y$ & $Y$ & $Y$ & $Y$ & $Y$ & $Y$ & $Y$ & $Y$ & $Y$ & $Y$ & $\mathrm{~N}$ & $Y$ & $Y$ \\
\hline $\mathrm{N}$ & $\mathrm{N}$ & $\mathrm{N}$ & $\mathrm{N}$ & $Y$ & $Y$ & $Y$ & $\mathrm{~N}$ & $\mathrm{~N}$ & $Y$ & $\mathrm{~N}$ & $Y$ & $\mathrm{~N}$ & $\mathrm{~N}$ & $\mathrm{~N}$ & $\mathrm{~N}$ & $\mathrm{~N}$ & $\mathrm{~N}$ & $\mathrm{~N}$ & $Y$ & $Y$ & $\mathrm{~N}$ \\
\hline$N$ & $N$ & $\mathrm{~N}$ & $Y$ & $Y$ & $N$ & $N$ & $N$ & $N$ & $\mathrm{~N}$ & $\mathrm{~N}$ & $N$ & $N$ & $N$ & $N$ & $\mathrm{~N}$ & $\mathrm{~N}$ & $\mathrm{~N}$ & $N$ & $\mathrm{~N}$ & $\mathrm{~N}$ & $N$ \\
\hline$N$ & $Y$ & $Y$ & $Y$ & $Y$ & $Y$ & $Y$ & $Y$ & $Y$ & $Y$ & $Y$ & $Y$ & $Y$ & $Y$ & $Y$ & $Y$ & $Y$ & $Y$ & $Y$ & $Y$ & $Y$ & $N$ \\
\hline$Y$ & $Y$ & $Y$ & $Y$ & $Y$ & $Y$ & $Y$ & $Y$ & $Y$ & $Y$ & $Y$ & $Y$ & $Y$ & $Y$ & $Y$ & $Y$ & $\mathrm{Y}$ & $Y$ & $Y$ & $Y$ & $Y$ & $Y$ \\
\hline$Y$ & $Y$ & $N$ & $N$ & $\mathrm{~N}$ & $Y$ & $\mathrm{~N}$ & $\mathrm{~N}$ & $\mathrm{~N}$ & $Y$ & $\mathrm{~N}$ & $\mathrm{~N}$ & $Y$ & $\mathrm{~N}$ & $Y$ & $\mathrm{~N}$ & $\mathrm{~N}$ & $\mathrm{~N}$ & $N$ & $\mathrm{~N}$ & $Y$ & $N$ \\
\hline$N$ & $\mathrm{~N}$ & $\mathrm{~N}$ & $\mathrm{~N}$ & $\mathrm{~N}$ & $Y$ & $\mathrm{~N}$ & $\mathrm{~N}$ & $\mathrm{~N}$ & $Y$ & $Y$ & $Y$ & $\mathrm{~N}$ & $\mathrm{~N}$ & $Y$ & $\mathrm{~N}$ & $\mathrm{~N}$ & $\mathrm{~N}$ & $\mathrm{~N}$ & $\mathrm{~N}$ & $\mathrm{~N}$ & $N$ \\
\hline$N$ & $\mathrm{~N} / \mathrm{A}$ & $Y$ & $N$ & $\mathrm{~N}$ & $Y$ & $\mathrm{~N}$ & $N$ & $N$ & $Y$ & $Y$ & $Y$ & $N$ & $\mathrm{~N}$ & $Y$ & $\mathrm{~N}$ & $N$ & $\mathrm{~N}$ & $N$ & $\mathrm{~N}$ & $\mathrm{~N}$ & $\mathrm{~N}$ \\
\hline$N$ & $\mathrm{~N}$ & $\mathrm{~N}$ & $\mathrm{~N}$ & $\mathrm{~N}$ & $N$ & $\mathrm{~N}$ & $\mathrm{~N}$ & $\mathrm{~N}$ & $\mathrm{~N}$ & $Y$ & $\mathrm{~N}$ & $N$ & $\mathrm{~N}$ & $N$ & $\mathrm{~N}$ & $\mathrm{~N}$ & $\mathrm{~N}$ & $\mathrm{~N}$ & $\mathrm{~N}$ & $Y$ & $N$ \\
\hline$Y$ & $Y$ & $Y$ & $Y$ & $Y$ & $Y$ & $Y$ & $Y$ & $Y$ & $Y$ & $Y$ & $Y$ & $\mathrm{~N}$ & $\mathrm{~N}$ & $\mathrm{~N}$ & $Y$ & $Y$ & $\mathrm{~N}$ & $Y$ & $Y$ & $\mathrm{~N}$ & $N$ \\
\hline$N$ & $Y$ & $\mathrm{~N}$ & $N$ & $Y$ & $Y$ & $Y$ & $Y$ & $\mathrm{~N}$ & $Y$ & $Y$ & $N$ & $N$ & $\mathrm{~N}$ & $\mathrm{~N}$ & $Y$ & $Y$ & $\mathrm{~N}$ & $\mathrm{~N}$ & $Y$ & $\mathrm{~N}$ & $N$ \\
\hline$N$ & $\mathrm{~N}$ & $Y$ & $N$ & $\mathrm{~N}$ & $\mathrm{~N}$ & $Y$ & $\mathrm{~N}$ & $Y$ & $Y$ & $\mathrm{~N}$ & $Y$ & $\mathrm{~N}$ & $\mathrm{~N}$ & $\mathrm{~N}$ & $Y$ & $Y$ & $\mathrm{~N}$ & $Y$ & $Y$ & $\mathrm{~N}$ & $\mathrm{~N}$ \\
\hline$Y$ & $Y$ & $Y$ & $Y$ & $Y$ & $Y$ & $Y$ & $Y$ & $Y$ & $Y$ & $Y$ & $Y$ & $Y$ & $Y$ & $Y$ & $Y$ & $Y$ & $Y$ & $Y$ & $Y$ & $Y$ & $Y$ \\
\hline $\mathrm{N}$ & $\mathrm{N}$ & $\mathrm{N}$ & $Y$ & $Y$ & $Y$ & $Y$ & $\mathrm{~N}$ & $\mathrm{~N}$ & $Y$ & $Y$ & $Y$ & $\mathrm{~N}$ & $\mathrm{~N}$ & $\mathrm{~N}$ & $Y$ & $\mathrm{~N}$ & $\mathrm{~N}$ & $\mathrm{~N}$ & $Y$ & $N$ & $N$ \\
\hline$Y$ & N/A & $\mathrm{N}$ & $\mathrm{N}$ & $\mathrm{N}$ & $\mathrm{N}$ & $N$ & $N$ & $\mathrm{~N}$ & $\mathrm{~N}$ & $\mathrm{~N}$ & $Y$ & $\mathrm{~N}$ & $Y$ & $Y$ & $\mathrm{~N}$ & $\mathrm{~N}$ & $\mathrm{~N}$ & $\mathrm{~N}$ & $\mathrm{~N}$ & $\mathrm{~N}$ & $N$ \\
\hline Y & Y & $Y$ & $Y$ & $Y$ & $Y$ & $Y$ & $Y$ & $Y$ & $Y$ & $Y$ & $Y$ & $Y$ & $Y$ & $Y$ & $Y$ & $Y$ & $Y$ & $Y$ & $Y$ & $Y$ & $Y$ \\
\hline$Y$ & $Y$ & $Y$ & $Y$ & $\mathrm{Y}$ & $Y$ & $Y$ & $Y$ & $\mathrm{~N}$ & $Y$ & $Y$ & $Y$ & $Y$ & $Y$ & $Y$ & $\mathrm{~N}$ & $Y$ & Y & $Y$ & $\mathrm{~N}$ & $Y$ & $Y$ \\
\hline $\mathrm{N}$ & $Y$ & $Y$ & $\mathrm{~N}$ & $\mathrm{~N} / \mathrm{A}$ & $Y$ & $Y$ & $Y$ & $Y$ & $Y$ & $Y$ & $Y$ & $Y$ & $Y$ & Y & $Y$ & N/A & $N / A$ & $Y$ & $\mathrm{~N}$ & $Y$ & $\mathrm{~N} / \mathrm{A}$ \\
\hline $\mathrm{N} / \mathrm{A}$ & $\mathrm{N} / \mathrm{A}$ & $\mathrm{N} / \mathrm{A}$ & $\mathrm{N} / \mathrm{A}$ & $\mathrm{N} / \mathrm{A}$ & $\mathrm{N} / \mathrm{A}$ & N/A & $\mathrm{N} / \mathrm{A}$ & N/A & $\mathrm{N} / \mathrm{A}$ & $\mathrm{N} / \mathrm{A}$ & $\mathrm{N} / \mathrm{A}$ & $\mathrm{N} / \mathrm{A}$ & $\mathrm{N} / \mathrm{A}$ & $\mathrm{N} / \mathrm{A}$ & $\mathrm{N} / \mathrm{A}$ & $\mathrm{N} / \mathrm{A}$ & $\mathrm{N} / \mathrm{A}$ & $\mathrm{N} / \mathrm{A}$ & $\mathrm{N} / \mathrm{A}$ & $\mathrm{N} / \mathrm{A}$ & $\mathrm{N} / \mathrm{A}$ \\
\hline Y & $\mathrm{Y}$ & $Y$ & $\mathrm{Y}$ & $\mathrm{Y}$ & $Y$ & Y & $Y$ & $Y$ & Y & $Y$ & $Y$ & $\mathrm{Y}$ & $\mathrm{Y}$ & $Y$ & $Y$ & $Y$ & Y & $Y$ & $\mathrm{Y}$ & $\mathrm{Y}$ & $\mathrm{N}$ \\
\hline$N$ & $Y$ & $Y$ & $Y$ & $Y$ & $Y$ & $Y$ & $N$ & $Y$ & Y & $Y$ & $Y$ & $Y$ & $Y$ & $Y$ & $Y$ & $Y$ & $Y$ & $Y$ & $Y$ & $Y$ & $Y$ \\
\hline$Y$ & $N$ & $Y$ & $Y$ & $Y$ & $Y$ & $Y$ & $Y$ & $Y$ & $Y$ & $Y$ & $Y$ & $Y$ & $Y$ & $N$ & $\mathrm{~N}$ & $Y$ & $\mathrm{~N}$ & $N$ & $Y$ & $Y$ & $N$ \\
\hline$N$ & $Y$ & $Y$ & $Y$ & $Y$ & $Y$ & $Y$ & $Y$ & $Y$ & $Y$ & $N$ & $N$ & $Y$ & $Y$ & $N$ & $\mathrm{~N}$ & $Y$ & $\mathrm{~N}$ & $N$ & $Y$ & $Y$ & $N$ \\
\hline$N$ & $N$ & $Y$ & $Y$ & $Y$ & $Y$ & $N$ & $N$ & $Y$ & $Y$ & $Y$ & $\mathrm{~N}$ & $\mathrm{~N}$ & $Y$ & $\mathrm{~N}$ & $\mathrm{~N}$ & $Y$ & $\mathrm{~N}$ & $Y$ & $Y$ & $Y$ & $N$ \\
\hline$Y$ & $Y$ & $Y$ & $Y$ & $Y$ & $Y$ & $Y$ & $Y$ & $Y$ & $Y$ & $Y$ & $Y$ & $Y$ & $Y$ & $Y$ & $Y$ & $Y$ & $N$ & $Y$ & $Y$ & $Y$ & $\mathrm{~N}$ \\
\hline
\end{tabular}

13. Mikalsen IB, Halvorsen T, Eide GE, Oymar K. Severe bronchiolitis in infancy: can asthma in adolescence be predicted? Pediatr Pulmonol. 2013;48(6):538-544.

14. Csonka P, Kaila M, Laippala P, Kuusela AL, Ashorn P. Wheezing in early life and asthma at school age: predictors of symptom persistence. Pediatr Allergy Immunol. 2000;11(4):225-229.

15. Neuman A, Bergstrom A, Gustafsson P, et al. Infant wheeze, comorbidities and school age asthma. Pediatr Allergy Immunol. 2014;25(4):380-386.

16. Chang TS, Lemanske RF Jr, Guilbert TW, et al. Evaluation of the modified asthma predictive index in high-risk preschool children. J Allergy Clin Immunol Pract. 2013;1(2):152-156.

17. Klaassen EM, van de Kant KD, Jöbsis Q, et al. Exhaled biomarkers and gene expression at preschool age improve asthma prediction at 6 years of age. Am J Respir Crit Care Med. 2015;191(2):201-207.

18. Caudri D, Wijga A, A Schipper CM, et al. Predicting the long-term prognosis of children with symptoms suggestive of asthma at preschool age. J Allergy Clin Immunol. 2009;124(5):903-910.e1-7.

19. Frank PI, Morris JA, Hazell ML, Linehan MF, Frank TL. Long term prognosis in preschool children with wheeze: longitudinal postal questionnaire study 1993-2004. BMJ. 2008;336(7658):1423-1426.
20. Amat F, Vial A, Pereira B, Petit I, Labbe A, Just J. Predicting the longterm course of asthma in wheezing infants is still a challenge. ISRN Allergy. 2011;2011:493624.

21. Reijonen TM, Kotaniemi-Syrjanen A, Korhonen K, Korppi M. Predictors of asthma three years after hospital admission for wheezing in infancy. Pediatrics. 2000;106(6):1406-1412.

22. Caudri D, Wijga AH, Hoekstra MO, et al. Prediction of asthma in symptomatic preschool children using exhaled nitric oxide, Rint and specific IgE. Thorax. 2010;65(9):801-807.

23. Leonardi NA, Spycher BD, Strippoli MP, Frey U, Silverman M, Kuehni CE. Validation of the Asthma Predictive Index and comparison with simpler clinical prediction rules. J Allergy Clin Immunol. 2011;127(6):1466-1472.e6.

24. Devulapalli CS, Carlsen KC, Håland G, et al. Severity of obstructive airways disease by age 2 years predicts asthma at 10 years of age. Thorax. 2008;63(1):8-13.

25. To T, Gershon A, Wang C, Dell S, Cicutto L. Persistence and remission in childhood asthma: a population-based asthma birth cohort study. Arch Pediatr Adolesc Med. 2007;161(12):1197-1204. 
26. Hyvarinen MK, Kotaniemi-Syrjänen A, Reijonen TM, PiippoSavolainen E, Korppi M. Eosinophil activity in infants hospitalized for wheezing and risk of persistent childhood asthma. Pediatr Allergy Immunol. 2010;21(1 Pt 1):96-103.

27. Sherrill DL, Stein R, Halonen M, Holberg CJ, Wright A, Martinez FD. Total serum IgE and its association with asthma symptoms and allergic sensitization among children. J Allergy Clin Immunol. 1999;104(1): 28-36.

28. Oostveen E, Dom S, Desager K, Hagendorens M, De Backer W, Weyler J. Lung function and bronchodilator response in 4-year-old children with different wheezing phenotypes. Eur Respir J. 2010;35(4): 865-872.

29. Turner SW, Palmer LJ, Rye PJ, et al. The relationship between infant airway function, childhood airway responsiveness, and asthma. Am J Respir Crit Care Med. 2004;169(8):921-927.
30. Delacourt C, Benoist MR, Waernessyckle S, et al. Relationship between bronchial responsiveness and clinical evolution in infants who wheeze: a four-year prospective study. Am J Respir Crit Care Med. 2001;164(8 Pt 1): 1382-1386.

31. Singer F, Luchsinger I, Inci D, et al. Exhaled nitric oxide in symptomatic children at preschool age predicts later asthma. Allergy. 2013;68(4):531-538.

32. Smolinska A, Klaassen EM, Dallinga JW, et al. Profiling of volatile organic compounds in exhaled breath as a strategy to find early predictive signatures of asthma in children. PLoS One. 2014;9(4):e95668.

33. Clough JB, Keeping KA, Edwards LC, Freeman WM, Warner JA, Warner JO. Can we predict which wheezy infants will continue to wheeze? Am J Respir Crit Care Med. 1999;160(5 Pt 1):1473-1480.

34. Yamada Y, Yoshihara S, Arisaka O. Creola bodies in wheezing infants predict the development of asthma. Pediatr Allergy Immunol. 2004; 15(2):159-162.
Journal of Asthma and Allergy

\section{Publish your work in this journal}

The Journal of Asthma and Allergy is an international, peer-reviewed open access journal publishing original research, reports, editorials and commentaries on the following topics: Asthma; Pulmonary physiology; Asthma related clinical health; Clinical immunology and the immunological basis of disease; Pharmacological interventions and

\section{Dovepress}

new therapies. This journal is included in PubMed. The manuscript management system is completely online and includes a very quick and fair peer-review system, which is all easy to use. Visit http://www. dovepress.com/testimonials.php to read real quotes from published authors.

Submit your manuscript here: https://www.dovepress.com/journal-of-asthma-and-allergy-journal 